The Jackson Laboratory

The Mouseion at the JAXlibrary

Faculty Research 2020

Faculty Research

$12-9-2020$

\title{
The involvement of neuroimmune cells in adipose innervation.
}

Magdalena Blaszkiewicz

Elizabeth Wood

Sigi Koizar

Jake Willows

Ryan Anderson

See next page for additional authors

Follow this and additional works at: https://mouseion.jax.org/stfb2020

Part of the Life Sciences Commons, and the Medicine and Health Sciences Commons 


\section{Authors}

Magdalena Blaszkiewicz, Elizabeth Wood, Sigi Koizar, Jake Willows, Ryan Anderson, Yu-Hua Tseng, James W Godwin, and Kristy L Townsend 


\title{
The involvement of neuroimmune cells in adipose innervation
}

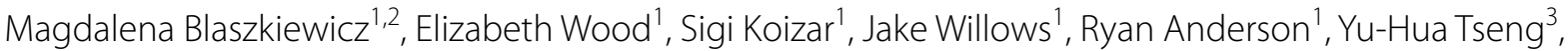 \\ James Godwin ${ }^{4,5}$ and Kristy L. Townsend ${ }^{1,2,6^{*}}$ (D)
}

\begin{abstract}
Background: Innervation of adipose tissue is essential for the proper function of this critical metabolic organ. Numerous surgical and chemical denervation studies have demonstrated how maintenance of brain-adipose communication through both sympathetic efferent and sensory afferent nerves helps regulate adipocyte size, cell number, lipolysis, and 'browning' of white adipose tissue. Neurotrophic factors are growth factors that promote neuron survival, regeneration, and plasticity, including neurite outgrowth and synapse formation. Peripheral immune cells have been shown to be a source of neurotrophic factors in humans and mice. Although a number of immune cells reside in the adipose stromal vascular fraction (SVF), it has remained unclear what roles they play in adipose innervation. We previously demonstrated that adipose SVF secretes brain derived neurotrophic factor (BDNF).

Methods: We now show that deletion of this neurotrophic factor from the myeloid lineage of immune cells led to a'genetic denervation' of inguinal subcutaneous white adipose tissue (scWAT), thereby causing decreased energy expenditure, increased adipose mass, and a blunted UCP1 response to cold stimulation.
\end{abstract}

Results: We and others have previously shown that noradrenergic stimulation via cold exposure increases adipose innervation in the inguinal depot. Here we have identified a subset of myeloid cells that home to scWAT upon cold exposure and are $\mathrm{Ly}_{6} \mathrm{C}^{+} \mathrm{CCR} 2^{+} \mathrm{C} \times 3 \mathrm{CR} 1^{+}$monocytes/macrophages that express noradrenergic receptors and BDNF. This subset of myeloid lineage cells also clearly interacted with peripheral nerves in the scWAT and were therefore considered neuroimmune cells.

Conclusions: We propose that these myeloid lineage, cold induced neuroimmune cells (CINCS) are key players in maintaining adipose innervation as well as promoting adipose nerve remodeling under noradrenergic stimulation, such as cold exposure.

Keywords: Innervation, White adipose tissue (WAT), Energy expenditure, Browning, CINCs, Cold-induced neuroimmune cells, BDNF, Monocyte/macrophage

\section{Introduction}

In order for the central nervous system (CNS) to regulate functions of distal organs and tissues, peripheral nervous system (PNS) innervation needs to be maintained and properly coordinated. It has been demonstrated

*Correspondence: kristy.townsend@osumc.edu

${ }^{6}$ The Ohio State University, 1014 Biomedical Research Tower, 460 W 12th Ave, Columbus, $\mathrm{OH} 43210$, USA

Full list of author information is available at the end of the article repeatedly that loss of innervation of the adipose organ (by surgical or chemical means) led to dysfunction of the tissue and disruption to whole body energy homeostasis. Denervation of brown adipose tissue (BAT) greatly impairs the energy expending process of adaptive thermogenesis (Dulloo and Miller 1984a, b; Minokoshi et al. 1986; Desautels et al. 1986), while denervation of white adipose tissue (WAT) results in fat mass accumulation via hyperplasia and impaired lipolysis (Bowers et al. 2004; Foster and Bartness 2006; Harris 2012). Furthermore, 
we have demonstrated that nerves in scWAT undergo remodeling in response to environmental stimuli (cold, exercise), and exhibit signs of neuropathy in obesity/diabetes, as well as with aging (Blaszkiewicz et al. 2019).

The maintenance of proper neural innervation is facilitated by neurotrophic factors (NFs) both in the CNS (Gray et al. 2013) and PNS (Terenghi 1999). NFs are nerve growth factors that support nerve health, survival, and plasticity. BDNF is one member of the neurotrophin family of NFs, which in mammals also includes nerve growth factor (NGF), Neurotrophin-3 (NT-3), and Neurotrophin-4/5 (NT-4/5). Neurotrophins signal predominantly through Trk receptors on nerves, through which they are endocytosed and, in peripheral nerves, transported in a retrograde manner to the nerve cell body, located in the ganglia. BDNF has been well studied for its role in hippocampal synaptic plasticity in the adult brain (An et al. 2008; Kleim et al. 2006; Fritsch et al. 2010), as well as learning and exercise-related neurogenesis (Tapia-Arancibia et al. 2004). BDNF is also an important modulator of energy balance, both appetite and energy expenditure, through its actions in the CNS (Rios et al. 2001; Unger et al. 2007; An et al. 2015). Deletion of $B d n f$ in the ventromedial and dorsomedial regions of the hypothalamus resulted in an obesity phenotype due to hyperphagic behavior (Unger et al. 2007). Obesity is associated with lower serum levels of BDNF in humans (Roth et al. 2013; Araki et al. 2014), while dietary restriction normalizes BDNF deficits in the brain in a mouse model of Huntington's disease (Duan et al. 2003). Animal studies have shown that central and peripheral administration of BDNF reduced food intake and hyperglycemia and increased energy expenditure, via CNS mediated mechanisms (Nakagawa et al. 2000; Nonomura et al. 2001; Xu et al. 2003a). As review by Xu and Xie, genetic mutations in human BDNF and its receptor TrkB result in morbid early-onset obesity (Xu and Xie 2016); furthermore, genome wide associated studies (GWAS) have identified single nucleotide polymorphisms (SNPs) in or near $B D N F$ to be associated with increased body mass index (BMI) (Xu and Xie 2016).

Despite these strong correlations between altered function of BDNF and its receptor TrkB with obesity, this growth factor has been predominately studied only in the CNS. A few studies have clearly shown that NFs, including BDNF, are present in adipose tissue (Sornelli et al. 2009; Hausman et al. 2006; Bernhard et al. 2013), but the cellular source of BDNF in adipose had not been determined. In adipose specific (FABP4-Cre) knock-outs of BDNF or TrkB, only CNS effects were apparent (not surprising, given off-target brain effects of this cre line) (Nakagomi et al. 2015). Using instead an adipoq-cre (mature adipocyte-specific line) there was no obesity in a BDNF or a TrkB knock-out (KO), and the BDNF KO showed no difference in adipose BDNF levels (Nakagomi et al. 2015). Together, these findings suggested that mature adipocytes are not the cellular source of BDNF (Nakagomi et al. 2015), which we have confirmed in this study by demonstrating predominance of BDNF expression in the SVF. NFs are secreted by glial cells in the brain (Goss et al. 1998) and Schwann cells in peripheral tissues (Madduri and Gander 2010). However, other cell types, predominantly immune cells, are also known sources of NFs (Leon et al. 1994; Kobayashi et al. 2002; Noga et al. 2003; Lambiase et al. 1997; Kerschensteiner et al. 1999), but are less studied.

As part of the immune response to injury, immune cells are critical players in wound healing, regeneration, and remodeling of various tissues. They are an important component of the adipose organ where they modulate the inflammatory response, clear the tissue of apoptotic cells, and mediate adipose tissue remodeling during obesity through an influx of monocytes (undifferentiated macrophages), neutrophils, T cells, B cells and mast cells (Weisberg et al. 2003; Winer et al. 2011; Rausch et al. 2008; Elgazar-Carmon et al. 2008; Liu et al. 2009; Strissel et al. 2010). Macrophages and their monocyte precursors are myeloid lineage immune cells and comprise the highest fraction of immune cells present in adipose tissue (Grant et al. 2013). They are highly heterogeneous cells that are polarized by environmental stimuli to evoke differential responses within a tissue, including secretion of cytokines.

In a simplistic paradigm, classically activated macrophages (M1) act in a pro-inflammatory manner, while alternatively activated macrophages (M2) produce an anti-inflammatory response. The reality is much more nuanced. Coordination between both M1 and M2 macrophages is essential for tissue repair and remodeling after injury, as is the recruitment of monocytes/macrophages to injury site in order to initiate the repair process. Both M1 and M2 cells retain phagocytic behavior. During obesity, M1 adipose tissue macrophages (ATMs) greatly increase in number without an influx of resolving M2 macrophages, thus contributing to a chronic state of tissue inflammation (Hui et al. 2015). Inflamed, insulin-resistant adipose tissue histology is characterized by macrophage crown-like structures surrounding hypertrophic, hypoxic and dying adipocytes. On the other hand, it has been suggested that cold-induced browning of adipose promotes an M2 phenotype in ATMs (Hui et al. 2015), possibly promoting tissue remodeling and potentially serving as a source of NFs in adipose tissue. Importantly, the immunology field has uncovered that M1 and M2 designations are an oversimplification, and in reality many immune cells express markers of both 
subtypes and may be inter-converting between these two polarities, but this concept has not yet been fully explored in adipose tissues.

Although myeloid cells, including monocytes and macrophages, from peripheral blood have been shown to store and release NFs (Rost et al. 2005), it is still unclear what role these immune cells play in peripheral tissue or organ neural innervation, and it remains unknown how and if adipose-resident and infiltrating immune cells are stimulated to release NFs that act locally. Microglia, the CNS resident myeloid cells that are most similar to macrophages, are an accepted source of BDNF in the brain (Parkhurst et al. 2013) and increase secretion of BDNF in response to neuroinflammation (Lai et al. 2018). Microglial-derived BDNF in the CNS promotes hippocampal synaptic plasticity (Parkhurst et al. 2013) and neurogenesis (Gemma and Bachstetter 2013). We hypothesized that myeloid lineage cells may play a similar role in adipose tissue, and generated a myeloid specific BDNF KO mouse model by crossing $L y s M C r e^{ \pm}$and $B D N F^{f l f l}$ mice. Here we report a role for myeloid derived BDNF in the specific maintenance of scWAT innervation, and identify a subpopulation of monocyte/macrophages $\left(\mathrm{Ly}_{6 \mathrm{C}}{ }^{+} \mathrm{CCR} 2^{+} \mathrm{Cx} 3 \mathrm{CR} 1^{+}\right)$that infiltrate adipose tissue in response to cold stimulation and express BDNF.

\section{Materials and methods}

\section{Mice, metabolic phenotyping, and in vivo analyses}

\section{Animals}

The following mouse strains were obtained from The Jackson Laboratory: C57BL/6J (Stock \# 000664); LysMCre $\pm\left(B 6.129 P 2-L y z 2 / J, \quad\right.$ Stock \# 004781); BDNF ${ }^{\text {fl/fl }}$ (Bdnf $^{\text {tm3Jae }} / J$, Stock \# 004339); R26R-EYFP (B6.129X1Gt(ROSA)26Sortm1(EYFP)Cos/J, Stock \# 006148); Cx3CR1-EGFP (B6.129P2(Cg)-Cx3cr1tm1Litt/J, Stock \# 005582). Animals with myeloid specific deletion of BDNF (LysMCre ${ }^{ \pm}:: B D N F^{-/-}$) were generated in our facility by crossing mice heterozygous for the myeloid -specific cre transgene (LysMCre ${ }^{ \pm}$) with mice homozygous for floxed BDNF. Reporter mice were generated by crossing LysMCre ${ }^{ \pm} \times \mathrm{BDNF}^{\mathrm{ffl}} \times \mathrm{R} 26 \mathrm{R}-\mathrm{EYFP}$. For all LysMCre $^{-/-}:: B D N F^{f / f l}(\mathrm{CON})$ and LysMCre ${ }^{ \pm}: B D N F^{-/-}$ (KO) studies only male mice were used. Animals were housed 3-5 to a cage providing for socialization, in a monitored temperature and humidity-controlled environment with $12 / 12 \mathrm{~h}$ light/dark cycle. Cages were replaced weekly. Ad libitum access to food and water was maintained. For all studies animals were sacrificed using $\mathrm{CO}_{2}$ followed by cervical dislocation.

\section{Dietary fat interventions and food intake}

Adult male LysMCre ${ }^{-/-}:: B D N F^{f / f l} \quad(\mathrm{CON})$ and LysMCre $^{ \pm}:: B D N F^{--}$(KO) mice were fed a $45 \%$ HFD diet from Research Diets (New Brunswick, NJ) for up to 11 weeks. Mice were housed 2-3 per cage, at room temperature. Body weight was measured weekly. Food intake was measured daily for 7 days, then weekly until the end of the experiment. Adiposity was assessed at the end of the study by weighing intact adipose depots after surgical removal.

\section{CLAMS}

Adult male $L_{y s M C r e^{-/}}:: B D N F^{f l f l} \quad(\mathrm{CON})$ and $L_{\text {LyMCre }}^{ \pm}:: B D N F^{-/-}(\mathrm{KO})$ mice were assessed in metabolic cages. Metabolic cage analyses were conducted in a Comprehensive Laboratory Animal Monitoring System (CLAMS; Columbus Instruments, Columbus, $\mathrm{OH}$ ), for measurement of oxygen consumption $\left(\mathrm{VO}_{2}\right)$ and carbon dioxide production $\left(\mathrm{VCO}_{2}\right)$, from which both respiratory exchange ratio (RER), and energy expenditure (Heat) were calculated: $R E R=V \mathrm{CO}_{2} / \mathrm{VO}_{2}$; Energy expenditure (heat) $=\mathrm{CV}^{*} \mathrm{VO}_{2}$ cal $/ \mathrm{hr}$, where $\mathrm{CV}$ is the "caloric value" as given by $C V=(3.815+1.232) * R E R$. Animals were single housed in a bedding free cage, at room temperature on a $12 \mathrm{~h}$ light/dark cycle. Mice were acclimated for 24-48 h, after which $\mathrm{VO}_{2}, \mathrm{VCO}_{2}, \mathrm{RER}$, and Heat were measured every $15 \mathrm{~min}$ for 3 days $(72 \mathrm{~h})$. Waveform analysis of CLAMS data was performed by matching every 15 min measurement across all three 24 h-cycles. Two-way repeated measures analysis of variance (RM, ANOVA) was performed for average $\mathrm{VO}_{2}, \mathrm{VCO}_{2}$, RER, and Heat per group. An uncorrected Fisher's Least Significance Difference test was performed for each time point between dietary groups as a post-hoc test. Interaction $P$ values are reported, which represent differences in $24 \mathrm{~h}$ data between groups, as well as multiple comparison results for differences which were only day/night phase specific.

\section{CL316,243 injections}

Adult (12-13 week old) male C57BL/6 mice received daily intraperitoneal (i.p.) injections of ADR $\beta 3$ agonist CL316,243 (Tocris Bioscience, Bristol, U.K.; Cat \# 1499), at $1.0 \mathrm{mg} / \mathrm{kg} \mathrm{BW}$ or an equivalent amount of sterile saline, for $10-14$ days.

\section{Cold exposure experiments}

All cold exposure was carried out in a diurnal incubator (Caron, Marietta, OH, USA) at $5{ }^{\circ} \mathrm{C}$, and a $12 \mathrm{~h} \mathrm{light/dark}$ cycle. Animals were housed two to a cage and continuously cold exposed for 3-14 days.

\section{Glucose tolerance test (GTT)}

Adult male LysMCre ${ }^{-/-}: B D N F^{f l f l} \quad(\mathrm{CON})$ and LysMCre $^{ \pm}:: B D N F^{-1-}(\mathrm{KO})$ mice were fasted overnight for $16 \mathrm{~h}$, after which they received an i.p. bolus injection 
of $1 \mathrm{~g} / \mathrm{kg}$ glucose. Blood glucose was measured using tail vein blood with a hand-held glucometer (OneTouch UltraMini, LifeScan, Milpitas, CA, Johnson \& Johnson, New Brunswick, NJ), at time 0 and at intervals of $15 \mathrm{~min}$, $30 \mathrm{~min}$, and $60 \mathrm{~min}$ after injection.

\section{Western blots}

Protein lysates were prepared by homogenizing frozen whole adipose depots in RIPA buffer using a Bullet Blender (Next Advance, Averill Park, NY), followed by Bradford Assay, and preparation of equal-concentration lysates in Laemmli buffer. $60 \mu \mathrm{g}$ of protein was loaded per lane of a $10 \%$ polyacrylamide gel, and following gel running, proteins were transferred to PVDF membranes for antibody incubation. Primary antibodies used included: anti-PGP9.5 (Abcam, Cambridge, U.K. Cat. \#10404 RRID:AB_297145 and \#108986 RRID:AB_10891773) used at a 1:1000 and 1:500 dilutions respectively; anti-UCP1 (Abcam, Cambridge, U.K. Cat. \#10983; RRID:AB_2241462) used at 1:1000 dilution, anti-TH (Millipore Cat. \# AB152; RRID:AB_390204; Merck Millipore, Burlington, MA), anti- $\beta$-tubulin (Cell Signaling Technology, Danvers, MA, USA; Cat. \# 2146; RRID:AB_2210545), were all used at 1:1000 dilution. Secondary antibody was anti-rabbit HRP (Cell Signaling Ct \# 7074; RRID:AB_2099233), used at a 1:3000 dilution. Blots were visualized with enhanced chemiluminescence (ECL; Pierce) on a Syngene G:BOX. Protein expression of PGP9.5, TH, and UCP1 was normalized to either $\beta$-tubulin or $\beta$-actin and quantified in ImageJ.

\section{Collection of adipose secretions and BDNF ELISA}

BAT depots were dissected, weighed and minced in a petri dish containing DMEM (high-glucose, serumfree). Minced tissue was transferred to a $15 \mathrm{~mL}$ conical tube with $5 \mathrm{~mL}$ DMEM (loosely capped to keep tissue oxygenated) and placed in a shaking water bath at $37^{\circ} \mathrm{C}$. Secretions were collected at time $0,1 \mathrm{~h}, 2 \mathrm{~h}$, and $3 \mathrm{~h}$ (1 $\mathrm{mL}$ collected from conical tube at each time point and replaced with $1 \mathrm{~mL}$ fresh DMEM). Secretions were stored at $-80{ }^{\circ} \mathrm{C}$ until processing. For ELISA, protein secretions were concentrated using Amicon ${ }^{\circledR}$ Ultra Centrifugal Filters, Ultracel ${ }^{\circledR}-100 \mathrm{~K}$ (Millipore, Burlington, MA USA; Cat. \# UFC510096), per manufacturer's instructions. Mouse BDNF PicoKine ${ }^{\mathrm{TM}}$ ELISA Kit (Boster Biological Technology, Pleasanton, CA, USA; Cat\# EK0309) was used per manufacturer's instruction to determine amount of BDNF present in adipose active secretions.

\section{Thyroid hormone ELISA}

Mouse sera were used to measure circulating levels of thyroxine (T4) and triiodothyronine (T3). Circulating concentrations were determined by Enzyme-Linked
Immunosorbant Assays (ELISA) at Maine Medical Center Research Institute's Core Facilities (Scarborough, ME).

\section{SVF isolation}

Bilateral whole inguinal adipose depots were quickly dissected and weighed. Tissue was minced in $37{ }^{\circ} \mathrm{C}$ prewarmed DMEM (high glucose, serum free) containing $2 \mathrm{mg} / \mathrm{mL}$ Roche Collagenase A (Millipore-Sigma, St. Louis, MO; Cat\# 10103586001) at a volume of $10 \mathrm{~mL} /$ depot. Minced tissue with collagenase containing DMEM was placed in a $50 \mathrm{~mL}$ conical tube and transferred to a shaking water bath $\left(350 / \mathrm{min}\right.$ rotation) at $37{ }^{\circ} \mathrm{C}$. Every 10 min cells were dispersed by vortex and pipette mixing. Full dissociation was usually achieved within $2 \mathrm{~h}$, when adipocytes were clearly visible and all tissue was dissociated. Dissociated media was poured through $100 \mu \mathrm{m}$ cell strainers, rinsed with DMEM and centrifuged at $500 \times g$ for $10 \mathrm{~min}$ to separate adipocytes from SVF. After centrifugation adipocytes were collected (found floating on top); remainder of DMEM was removed sparing the SVF pellet. SVF pellet was incubated with $500 \mu \mathrm{L}$ of RBC lysis buffer on ice for $2 \mathrm{~min}$, after which $2 \mathrm{~mL}$ of DMEM with serum was added to stop lysis. Cells were centrifuged at $500 \times g$ for $5 \mathrm{~min}$ at $4{ }^{\circ} \mathrm{C}$, and either collected for RNA or resuspended in FACS/MACS buffer for cell sorting.

\section{Magnetic-activated cell sorting (MACS)}

SVF from bilateral whole inguinal adipose depots was isolated as described above and resuspended in degassed buffer (1XPBS pH 7.2, 0.5\% BSA and 2 mM EDTA). Single-cell suspensions were sorted on the MidiMACS Quadro magnetic-activated cell separator system (Miltenyi Biotec, Bergisch Gladbach, Germany) according to manufactures instructions. Briefly, cells were stained with primary PE-conjugated antibody, CD11b-PE (Cat \#130-098-087); a 1:10 antibody dilution per $10^{7}$ cells was used. Cells were incubated for $10 \mathrm{~min}$ at $4-8{ }^{\circ} \mathrm{C}$, washed, and centrifuged at $300 \times g$ for $10 \mathrm{~min}$. Washed cell pellet was resuspended in a 1:10 dilution of anti-PE microbeads included in Anti-PE MultiSort Kit (Cat. \#130-090757). Following $15 \mathrm{~min}$ incubation at $4-8{ }^{\circ} \mathrm{C}$, cells were washed and centrifuged as described above. Cells were resuspended in $500 \mu \mathrm{L}$ of buffer and passed through LS columns of the MACS separator. LS columns were prepped according to manufacturer's suggestion. Cells were washed three times, collected cells (CD11b-) were collected. LS columns were removed from the MACS separator and flushed with $5 \mathrm{~mL}$ of buffer to release the magnetically labeled cell fraction (CD11b+). MicroBeads were removed using MicroSort release reagent included in Anti-PE MultiSort Kit (Cat. \#130-090-757). MicroBead free $\mathrm{CD} 11 \mathrm{~b}+$ cell fraction was labeled for the secondary 
marker, Anti-F4/80-APC (Cat. \#130-102-942), following the same procedure as described for the primary marker, except that Anti-APC MicroBeads (Cat. \#130-090-855) were used.

\section{Fluorescence-activated cell sorting (FACS)}

SVF from bilateral whole inguinal adipose depots was isolated as described above. For cell sorting, the following 5 marker panel was used with DAPI exclusion for viability: Anti-Mouse Ly6C_BV570 (HK1.4), Anti-Mouse CD11b PE (M1/70), Anti-Mouse CX3CR1 PercP5.5, SA011F11), Anti-Mouse CD45-PE-Cy7 (30-F11), AntiMouse CCR2 A700 (475301). Sorting was performed on a BD ${ }^{\mathrm{TM}}$ FACSAria II ${ }^{\mathrm{TM}}$ cell sorter with SVF gated on CD45 and CD11b; CD45+CD11b- represented the non-myeloid population; $\mathrm{CD} 45^{+} \mathrm{CD} 11 \mathrm{~b}^{+}$myeloid fraction was gated on Ly6C, followed by CCR2 and Cx3CR1.

\section{Cell surface marker tSNE analysis of myeloid diversity in male and female mice}

Adult (13-15 week old) male and female control mice $\left(\mathrm{BDNF}^{\mathrm{fl} / \mathrm{fl}}\right)$ were cold exposed for 10 days in a diurnal incubator as described above. Following cold exposed SVF from bilateral whole inguinal adipose depots was isolated as described above. Single cell suspensions were treated with unlabeled FC receptor blocking antibody cocktail (CD16/CD32) in 50ul of FACS buffer (HBSS $+5 \mathrm{mM}$ EDTA $+2 \%$ FCS). Cells were then incubated in an "staining antibody cocktail" against 20 cell surface markers for $60 \mathrm{~min}$ at $4{ }^{\circ} \mathrm{C}$ in $100 \mu \mathrm{L}$. Cells were then washed in $1 \mathrm{~mL}$ of FACS buffer and centrifuged at $400 \times g$ for $7 \mathrm{~min}$, two times. Cells were then resuspended and analyzed on a five-laser 30-parameter FACSymphony A5 cytometer (BD Biocsiences, San Jose, USA) using DAPI exclusion for cell viability. For compensation of fluorescence spectral overlap, UltraComp eBeads (eBioscience, Inc.) were used following the manufacturer's protocols. FCS 3.0 files generated by flow cytometry were initially processed using FlowJo Software (Tree Star, Ashland, USA) for automated compensation. Standard manual hierarchical gating was performed to remove debris, cell doublets and (DAPI+) dead cells from analysis before gating on CD45+leukocyte populations. In preparation for performing the 20 marker tSNE leukocyte population analysis, the CD45+ population from each sample was down-sampled to 3000 events to normalize cellular input between samples. Using FlowJo, a concatemer of all samples was performed. An unbiased T-Distributed Stochastic Neighbor Embedding (tSNE) plugin algorithm was then run using defaults with 22 parameters, on the whole sample pool to obtain a multi-sample population reference map. Gating of each sample and experimental group was performed to generate tSNE maps for each condition. Differential cell clusters were gated and 20 marker histograms plots were used to predict cluster identities.

Antibodies used for adipose flow cytometric panel shown here: Anti-Mouse CD45-BUV395 (30-F11), AntiMouse B220_BUV496 (RA3-6B2), Anti-Mouse Ly-6G BUV563 (Clone 1A8), Anti-Mouse CD19 BUV661 (Clone 1D3), Anti-Mouse CD11b BUV737 (M1/70), AntiMouse NKp46_BV421 (29A1.4), Anti-Mouse CD62L BV510 (MEL-14), Anti-Mouse Ly6C_BV570 (HK1.4), Anti-Mouse CD3 BV605 (17A2), Anti-Mouse Mrc1 BV650 (C068C2), Anti-Mouse MHCII -I-A/I-E -BV711 (M5/114.15.2), Anti-Mouse NK1.1 BV785 (PK136), Anti-Mouse CD11c_FITC (HL3), Anti-Mouse CD80 PE (16-10A1), Anti-Mouse CD115 CF594 (AFS98), AntiMouse CX3CR1 PercP5.5 (SA011F11), Anti-Mouse CD64 PE-Cy7 (X54-5/7.1), Anti-Mouse CD14 APC (Sa28), Anti-Mouse CCR2 A700 (475301), Anti-Mouse F480 APC/Cy7 (BM8).

\section{Gene expression (qPCR)}

RNA was isolated from whole tissue depots using Trizol reagent, and total RNA extracted using a Zymo (Irvine, CA) kit. RNA yield was determined on a Nanodrop; cDNA was synthesized using a High Capacity Synthesis Kit (Applied Biosystems, Foster City, CA). Real-time quantitative (q)PCR was performed with SYBR Green (Bio-Rad, Hercules, CA) on a CFX96 instrument (BioRad, Hercules, CA).

\section{Histology \\ Adipose}

Immunofluorescent staining of $10 \%$ buffered formalin fixed, paraffin-embedded, $7 \mathrm{um}$ sections of adipose tissues was performed for detection of UCP1 (RRID:AB_2241462, 1:500, Abcam, Cambridge, UK. Cat. \#10983). Alexa 488 (2.5 $\mu \mathrm{g} \mathrm{mL}$, Molecular Probes, Eugene, OR, USA, Cat. \# A11070) was used as secondary antibody. Typogen Black staining was used to quench tissue autofluorescence (prior to antibody incubation) and also provided visualization of cell size, browning (multilocularity) and crown-like structures. Stained sections were mounted using Millipore mounting fluid (Burlington, MA USA; Cat. \# 5013) and 1 1/2 coverslips, and imaged on a Nikon Eclipse E400 epifluorescent microscope equipped with Nikon DS-fi2 camera. Wholemount adipose staining was performed as previously described (Blaszkiewicz et al. 2019; Willows et al. 2019) and imaged by widefield and confocal microscopy. Widefield imaging was performed on a Nikon E400 epifluorescence microscope with Hamamatsu ORCA-Flash4.0 V2 Digital CMOS monochrome camera (Hamamatsu Photonics K.K., C11440-22CU). 
Objectives used: Nikon CFI Plan Apochromat Lambda 10X (NA 0.45, WD $4.00 \mathrm{~mm}$, dry) and Nikon CFI Plan Fluor 40X (NA 0.75, WD $0.66 \mathrm{~mm}$, dry.) Images were processed using Nikon NIS-Elements software. Images captured on Hamamatsu ORCA-Flash4.0 V2 were pseudo colored. For confocal imaging a Leica TCS SP8 DLS microscope with HyD detectors was used. Fluorophores were excited with a white light laser tuned specifically for the excitation and emission spectra of EGFP. Objectives used: HC PL APO CS2 20X (NA 0.75, WD $0.62 \mathrm{~mm}$, dry) and HC PL APO CS2 63X (NA 1.40, WD $0.14 \mathrm{~mm}$, oil). Images were processed with LASX software and were either pseudo colored or left monochromatic. Primary antibodies included: PGP9.5 conjugated to Alexa 647 (1:200, Abcam, Cambridge, U.K. Cat. \#196173).

\section{Neuromuscular junction immunofluorescence, imaging, and analysis}

Soleus and medial gastrocnemius muscles were removed and fixed in a $2 \%$ PFA at $4{ }^{\circ} \mathrm{C}$ for $2 \mathrm{~h}$. Tissues were rinsed with $1 \mathrm{XPBS}$ and incubated in blocking buffer (1XPBS/2.5\%BSA/0.5-1\%Triton) at $4{ }^{\circ} \mathrm{C}$ for at least $24 \mathrm{~h}$ and up to 7 days. Following blocking muscles were teased, tendons and fat was removed, and tissue was flattened by being placed between two tightly-bound glass slides for at least $30 \mathrm{~min}$ at $4{ }^{\circ} \mathrm{C}$. Tissues were transferred to fresh blocking buffer at $4{ }^{\circ} \mathrm{C}$ for at least $12 \mathrm{~h}$. Immunostaining of innervation with primary antibodies was performed overnight at $4{ }^{\circ} \mathrm{C}$, followed by 1 XPBS washes on a rotating platform at $4{ }^{\circ} \mathrm{C}$ replacing PBS every $1 \mathrm{~h}$ for a total of 4-6 h. Tissues were incubated with secondary fluorescent antibodies in similar fashion as primary antibodies. Primary antibodies included: neurofilament-M (2H3, RRID:AB_531793, 1:500) and synaptic vesicles (SV2, RRID:AB_2315387, 1:250) from Developmental Studies Hybridoma Bank, (University of Iowa, USA). Secondary antibodies included: Alexa Fluor 488 at 1:500 (A21121) and alpha-bungarotoxin (BTX)-conjugated to Alexa Fluor 594 at 1:1000 (B13423) from Molecular Probes (Eugene, OR, USA). Tissues were mounted on microscope slides using Millipore mounting fluid (Burlington, MA USA; Cat. \# 5013) and 1 1/2 coverslips then sealed and allowed to set overnight. Stained sections were imaged on a Nikon Eclipse E400 epifluorescent microscope equipped with Nikon DS-fi2 camera. Brightness, contrast, and sharpness were adjusted in Microsoft PowerPoint. Up to $100 \mathrm{NMJs}$ were counted for each tissue, statistics were conducted in GraphPad PRISM software (La Jolla, CA, USA) using the multiple t-tests (one-per row) function.

\section{Statistical analysis}

For all animal experiments, mice were randomized to treatment groups to ensure no difference in starting body weight. All plots represent mean \pm SEM. Statistical calculations were carried out in Excel or GraphPad Prism software (La Jolla, CA, USA), utilizing ANOVA, Linear Regression, or Student's $T$-test as indications of significance (specified in Figure legends). Gene and protein expression data were normalized to a housekeeper and analyzed by either ANOVA or by Student's $t$-test, two-tailed, using Welch's correction when variance was unequal. Error bars are SEMs. For all figures, ${ }^{*} \mathrm{p}<0.05$, ${ }^{* * *} \mathrm{p}<0.01,{ }^{* * * * \mathrm{p}}<0.001, * * * * \mathrm{p}<0.0001$.

\section{Ethical statement}

All procedures and handling of animals were performed in accordance with the University of Maine's Institutional Animal Care and Use Committee (IACUC), to comply with the guidelines of the PHS Policy on Humane Care and Use of Laboratory Animals, and Guide for the Care and Use of Laboratory Animals. This study was approved by the University of Maine's IACUC, under protocol A2017-09-04.

\section{Results \\ BDNF is expressed primarily in adipose SVF}

We previously demonstrated that BDNF secretion increases from scWAT in response to noradrenergic stimulation, after administration of the $\beta-3$ adrenergic receptor (ADR 33 ) agonist CL316,243 (Blaszkiewicz et al. 2019). We then endeavored to determine which adipose compartment and cell type was the source of local BDNF secretion in scWAT. Adipose tissue is a heterogeneous organ and although adipocytes are the main cell type, numerous other cell types are contained within the SVF of adipose tissue. Adipose SVF consists predominantly of hematopoietic lineage cells including adipose tissue macrophages (ATMs (Strissel et al. 2010; Grant et al. 2013)), but also contains numerous other immune cell types, preadipocytes, vascular endothelial cells, and pericytes. To determine the compartmental source of adipose BDNF, adult male C57BL/6 mice were cold exposed and whole SVF was isolated from mature adipocytes of inguinal scWAT by collagenase dispersion. Gene expression analysis revealed that $B d n f$ was almost exclusively expressed in the SVF, while other common growth factors (nerve growth factor; NGF, and vascular endothelial growth factor, VEGFa) showed no difference of expression between SVF and mature adipocyte fractions $(p \leq 0.0001, p=0.1572, p=0.0767)$ (Fig. 1a).

Given the known expression of BDNF in immune cells, we sought to determine the contribution of 
myeloid-lineage BDNF to adipose innervation by creating a $\mathrm{KO}$ mouse model using Cre-Lox technology. $\mathrm{LysMCr}^{ \pm}$mice were bred to $B D N F^{f / f l}$ mice to generate LysMCre $^{ \pm}:: B D N F^{-/-}$(KO) animals, which lacked BDNF in myeloid lineage cells (Fig. 1b). (For the genotyping strategy, see Additional file 1: Figure S1A). Compared to littermate controls, $\mathrm{KO}$ animals exhibited a significant, although not complete, decrease of $B d n f$ in adipose SVF as measured by gene expression $(p=0.0001)$ (Fig. 1c). Likely additional SVF cell types also contribute to tissue BDNF levels. Since myeloid lineage cells are also expressed in the brain, and BDNF has been shown to play a role in energy balance via CNS control of satiety, we also investigated whether our KO model affected BDNF expression in the hypothalamus. Gene expression of $B d n f$ in the hypothalamus did not differ between $\mathrm{KO}$ animals and their littermate controls $(p=0.6132)$ (Fig. 1d). Physiological assessment using metabolic cages performed on $\mathrm{KO}$ animals and their littermate controls in the basal state revealed that $\mathrm{KO}$ mice had significantly lower energy expenditure $(p \leq 0.0001)$ (Fig. 1e) despite showing no difference in body weight or adiposity $(p=0.2735$, $p=0.6364$ ) (Additional file 1: Figure S1B).

\section{KO mice have a blunted response to cold stimulation}

Since a decrease in energy expenditure could be indicative of impaired sympathetic drive, we stimulated sympathetic nerve activity via cold exposure. When adult (22-23 week old) male mice were cold challenged at $5{ }^{\circ} \mathrm{C}$ for 4 days, $\mathrm{KO}$ and control animals maintained similar body weight $(p=0.0750)$ Fig. 2a, left panel). However, $\mathrm{KO}$ animals had a trend for increased adiposity $(p=0.1107)$ (Fig. 2a, right panel). As cold exposure stimulates catecholamine-induced lipolysis mediated through sympathetic nerves, we next investigated innervation of the inguinal scWAT depot following a 7-day cold challenge. Protein expression of the pan-neuronal marker PGP9.5 was markedly reduced in inguinal scWAT of male KO mice compared to littermate controls $(p=0.0025)$ (Fig. 2b, left panel). Protein expression of tyrosine hydroxylase (TH), a marker of sympathetic innervation and activation, was also drastically reduced in inguinal scWAT of $\mathrm{KO}$ animals compared to controls $(p=0.0200)$ (Fig. 2b, right panel). Gene expression of synaptic/innervation markers (Psd95, Sox10, Synapsin I, Synapsin II, Synaptopysisn) in inguinal scWAT also showed a coordinated trend to be decreased in $\mathrm{KO}$ animals $(p=0.386, p=0.126, p=0.155, p=0.130, p=0.728)$ (Additional file 1: Figure S1C), further indicating perturbations in scWAT innervation of $\mathrm{KO}$ animals. Together, these data indicated a 'genetic denervation' in this model.

Interestingly, gene expression of lipolytic markers Atgl and $H s l$ showed an increased trend in scWAT of KO animals $(p=0.081, p=0.078)$ (Additional file 1: Figure $\mathrm{S} 1 \mathrm{C})$. Loss of scWAT innervation potentially results in decreased lipolysis due to lack of SNS mediated release of norepinephrine. However, due to the critical role of lipolysis in facilitating thermoregulation during cold challenge, we suspect that lipolysis in $\mathrm{KO}$ animals is achieved by alternative, nerve-independent, pathways. For example, glucocorticoid-mediate lipolysis has been attributed to increased $\beta$-adrenergic responsiveness via direct signaling or indirectly by inducing secretion of angiopoietinlike 4 (Angptl4) (Gray et al. 2017; Nielsen et al. 2014).

Cold exposure induces expression of uncoupling protein 1 (UCP1) as required for adaptive thermogenesis, due to its ability to uncouple the mitochondrial respiratory chain resulting in a proton leak and heat production. UCP1 is therefore a unique marker of BAT and cold-induced 'browning' in scWAT. Gene expression of Ucp 1 in inguinal scWAT of 7-day cold exposed mice was reduced in $\mathrm{KO}$ animals compared to littermate controls $(p=0.0573)$ (Fig. 2c). Thyroid hormone potentiates sympathetic nervous system (SNS) activation of thermogenesis in BAT, but is produced via a distinct neuronal pathway from adipose sympathetic drive. We observed no changes in circulating thyroid hormones between $\mathrm{KO}$ and control (CON) animals $(p=0.9526$, $p=0.3471$ ) (Fig. 2d). Histological assessment of inguinal scWAT revealed what appeared like increased multilocularity suggestive of browning in $\mathrm{KO}$ animals (Fig. 2e, Typogen Black staining). However, there was a striking lack of UCP1 expression in these areas in KO tissues (Fig. 2e). Typogen Black (used here to reduce

\footnotetext{
(See figure on next page.)

Fig. 1 BDNF is expressed in scWAT SVF fraction; LysMCre ${ }^{ \pm . . B D N F}{ }^{-/-}(K O)$ mice have lower energy expenditure. Adult male CB57/BL6 mice were cold exposed at $5{ }^{\circ} \mathrm{C}$ and SVF was isolated from mature adipocytes of the inguinal scWAT depot. Differences in gene expression between adipose compartments of neurotrophic factors, Bdnf, Ngf, and Vegfa, is shown ( $p \leq 0.0001, p=0.1572, p=0.0767$, respectively) (a). Data analyzed by Student's $t$-test, two-tailed, $\mathrm{N}=4$. Illustration of $\mathrm{KO}$ model generation (b). BDNF gene expression in adipose SVF of $L y s M C e^{-/-}: . B D N F^{A / / f}$ (CON) versus LysMCre ${ }^{ \pm}: B D N F^{-1-}(\mathrm{KO})$ mice, $p=0.0001$ (c). Data analyzed by Student's t-test, two-tailed, $N=4$ per group. Gene expression of $B d n f$ in hypothalamus of LysMCre ${ }^{-1-.: B D N F^{f / f l}}(\mathrm{CON})$ versus LysMCre ${ }^{ \pm .: B D N F^{-1-}}(\mathrm{KO})$ mice, $p=0.6132$ (d). Data analyzed by Student's $t$-test, two-tailed, $N=5$ CON; $N=6 \mathrm{KO}$. Adult (8-12 week old) male CON and $\mathrm{KO}$ mice were assessed in metabolic cages (CLAMS). KO mice displayed lower energy expenditure represented as heat calculated from measures of $\mathrm{VO}_{2}$ and $\mathrm{VCO}_{2}$ over the whole $24 \mathrm{~h}, p \leq 0.0001$ (e). Waveform analysis of metabolic cage measurements taken at $15 \mathrm{~min}$ increments for $48 \mathrm{~h}$. Time of day is indicated on the $\mathrm{x}$-axis, animals were maintained on a $12 \mathrm{~h}$ light/dark cycle (black bars indicate dark cycle). For all error bars are SEMs
} 


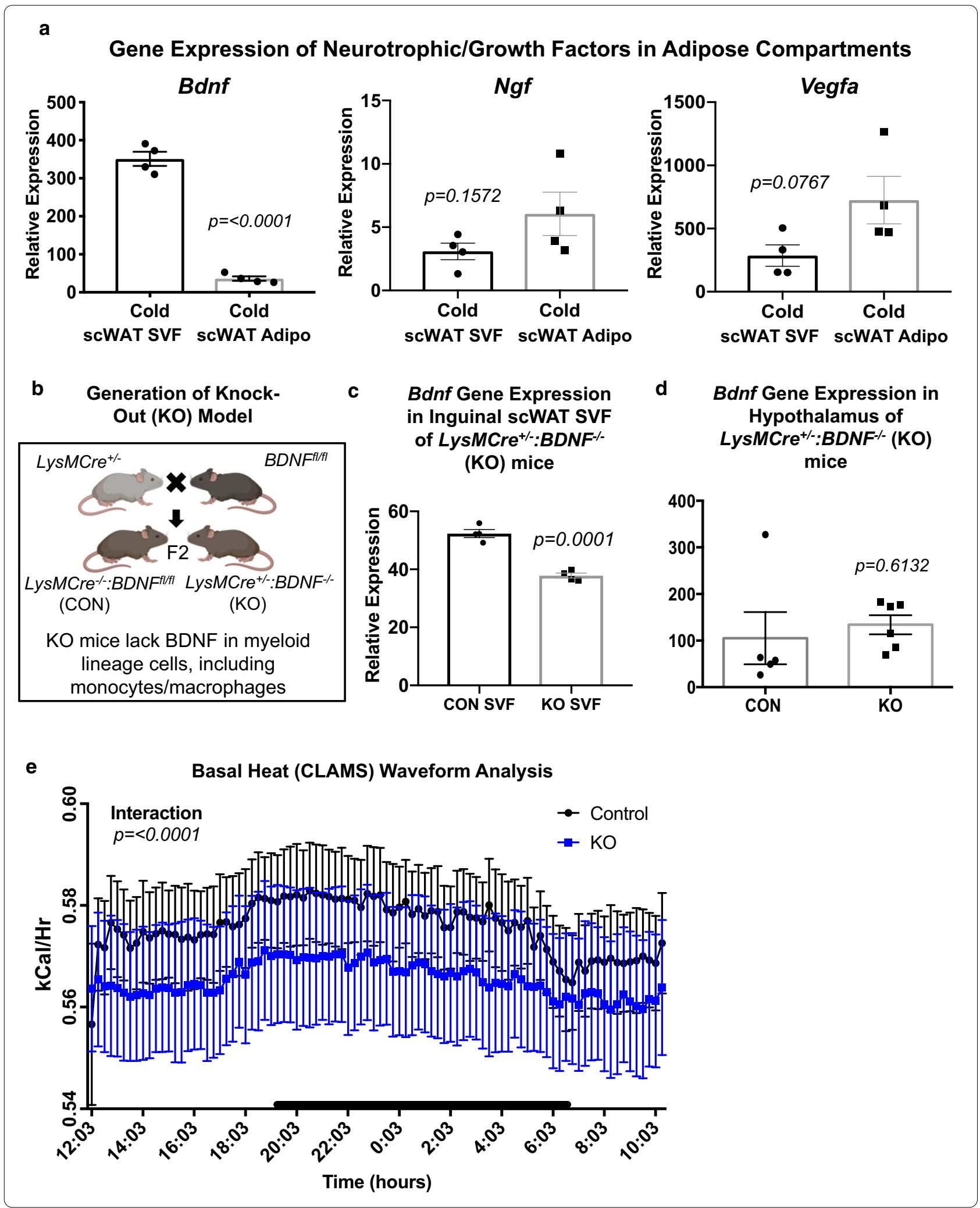


tissue autofluorescence) may also mark immune cells, thus there is potential for increased immune cell infiltration in the KO tissues as well. However, perilipin (a lipid droplet associated protein) staining of scWAT from KO animals clearly showed that the multilocular cells lacking UCP1 expression contained high amounts of lipid droplets (Fig. 2f, UCP1 immunofluorescence in red, perilipin immunofluorescence in green on serial sections). Preadipocytes maintain multilocular lipid droplets prior to differentiation, and considering that denervation of WAT increases hyperplasia, the observed multilocularity could more likely be areas of increased preadipocytes. In total, these findings demonstrate reduced thermogenic potential in denervated scWAT.

\section{Genetic denervation of scWAT in LysMCre ${ }^{ \pm}: B D N F^{-/-}$(KO) mice is depot specific}

We next sought to determine whether genetic denervation of scWAT in $\mathrm{KO}$ animals was restricted to this adipose tissue or extended to other organs. BDNF is a known myokine, and muscle is an energy expending tissue. We assessed innervation of fast twitch (gastrocnemius) and slow twitch (soleus) muscle in $\mathrm{CON}$ and $\mathrm{KO}$, by investigating occupancy of neuromuscular junctions (NMJs) at basal conditions in adult male mice. Immunostaining of the presynaptic nerve and vesicles (neurofilament and SV2 markers, respectively) with postsynaptic acetylcholine receptors was performed to allow visualization of NMJ (Additional file 1: Figure S2A, left panel). Following counts of occupied, partially occupied, and unoccupied NMJs it was determined that there was no evidence of neurodegeneration in the $\mathrm{NMJ}$ of $\mathrm{KO}$ animals (Additional file 1: Figure S2A, right panel). In the same animals we also assessed axon numbers of spinal (L5 ventral root), motor, and sensory nerves through cross-section imaging $(p=0.7344, p=0.3363, p=0.1469)$ (Additional file 1: Figure S2B). A lower axon count could reflect neuronal death in these larger PNS nerves, but no difference was observed between $\mathrm{CON}$ and $\mathrm{KO}$ animals.

Myeloid cells are also present in BAT tissue. We therefore wanted to evaluate whether a lack of BDNF in BAT myeloid cells would have an effect on this tissue's function. BAT of 7-day cold exposed 12-25 week old male $\mathrm{CON}$ and $\mathrm{KO}$ mice was evaluated. Protein expression of neuronal markers TH and PGP9.5 did not differ between $\mathrm{KO}$ and control mice $(p=0.7747, p=0.7680)$ (Additional file 1: Figure S3A), indicating that BDNF may not have an important neurotrophic role in BAT. Consistent with that, histological assessment of BAT revealed no difference in cellular morphology nor UCP1 expression (Additional file 1: Figure S3B). Indeed, when adult male C57BL/6 mice were cold exposed or treated with the pharmacological ADR $\beta 3$ agonist, CL316,243, no difference in BDNF secretion from BAT was observed when compared to basal conditions (not analyzed due to low $\mathrm{N}$ of control animals) (Additional file 1: Figure S3C). Together, these data supported scWAT depot specificity of our genetic denervation model, and BAT neuronal function may simply be due to increased sympathetic nerve activity and not changes in neural plasticity and neurite outgrowth in the tissue. Alternatively, a different neurotrophic factor, like NGF, may be more important for BAT than WAT.

\section{HFD feeding exacerbates fat mass accumulation in LysMCre $^{ \pm}:: B D N F^{-/-}(K O)$ mice}

Loss of sympathetic innervation to inguinal scWAT has been shown to increase depot mass (Bartness and Song 2007), however, in our genetic model of scWAT denervation, no difference in adiposity was observed under basal conditions (Additional file 1: Figure S1B) despite the observed decrease in energy expenditure (Fig. 1e). We next metabolically challenged $\mathrm{CON}$ and $\mathrm{KO}$ mice with a $45 \%$ high fat diet (HFD). Adult (25 week old) male CON

\footnotetext{
(See figure on next page.)

Fig. 2 LysMCre ${ }^{ \pm . . B D N F^{-/-}}(\mathrm{KO})$ have increased adiposity and impaired response to cold due to genetic denervation of scWAT. Adult (22-23 week old) male $\mathrm{LysMCre} e^{-/-. . B D N F^{f / f l}}(\mathrm{CON})$ and $L y s M C r e^{ \pm} .: B D N F^{-1-}(\mathrm{KO})$ mice were cold exposed at $5^{\circ} \mathrm{C}$ for 4 days; body weight and adiposity were compared between $\mathrm{CON}$ and $\mathrm{KO}$ groups, $p=0.0750$ and $p=0.1107$, respectively (a). Body and tissue weight data were analyzed by two-tailed Student's T-Test, $\mathrm{N}=5 \mathrm{CON}, \mathrm{N}=6 \mathrm{KO}$. Protein expression of PGP9.5 and tyrosine hydroxylase (TH) in inguinal scWAT was measured by Western blotting from adult (12-25 week old) 7 -day cold $\left(5^{\circ} \mathrm{C}\right.$ ) exposed WT/CON and $\mathrm{KO}$ male animals, $p=0.0025$ and $p=0.0200$, respectively (b). $\beta$-Tubulin was used as a loading control for normalization. Data were analyzed by two-tailed Student's T-Test, N=3WT/CON, N=4 KO, *denotes data that was removed from analysis due to lack of expression of loading control. Gene expression of Ucp1 was measured in adult (12-25 week old) 7-day cold $\left(5{ }^{\circ} \mathrm{C}\right)$ exposed WT/CON and KO males, $p=0.0573$ (c). Data were analyzed by two-tailed Student's T-Test, N =5 WT/CON, N=5 KO. Circulating thyroid hormones, triiodothyronine (T3), and thyroxine (T4) were measured by ELISA from serum of adult (22-23 week old) 4 -day cold ( $5^{\circ} \mathrm{C}$ ) exposed CON and $\mathrm{KO}$ male mice, $p=0.9526$ and $p=0.3471$, respectively (d). Data were analyzed by One-way ANOVA, with Tukey's multiple comparisons test, $\mathrm{N}=5 \mathrm{CON}, \mathrm{N}=6 \mathrm{KO}$. Immunofluorescent staining for UCP1 was performed on inguinal scWAT sections of adult (22-23 week old) male CON and $\mathrm{KO}$ mice following 4-day cold $\left(5^{\circ} \mathrm{C}\right)$ exposure $(\mathbf{e})$. Immunofluorescent staining for UCP1 and Perilipin was performed on inguinal scWAT sections of adult (22-23 week old) male KO mice following 4-day cold $\left(5^{\circ} \mathrm{C}\right)$ exposure (f). Typogen Black, used to quench lipid autofluorescence, provided staining cell morphology which was visualized under brightfield microscopy. Overlay is immunofluorescence over brightfield of the same area (f). Images were acquired with a $10 \mathrm{X}$ or $40 \mathrm{X}$ objective and are representative of $\mathrm{N}=5 \mathrm{CON}, \mathrm{N}=8 \mathrm{KO}$ (E) and $\mathrm{N}=4 \mathrm{KO}$ (f). For all error bars are SEMs
} 


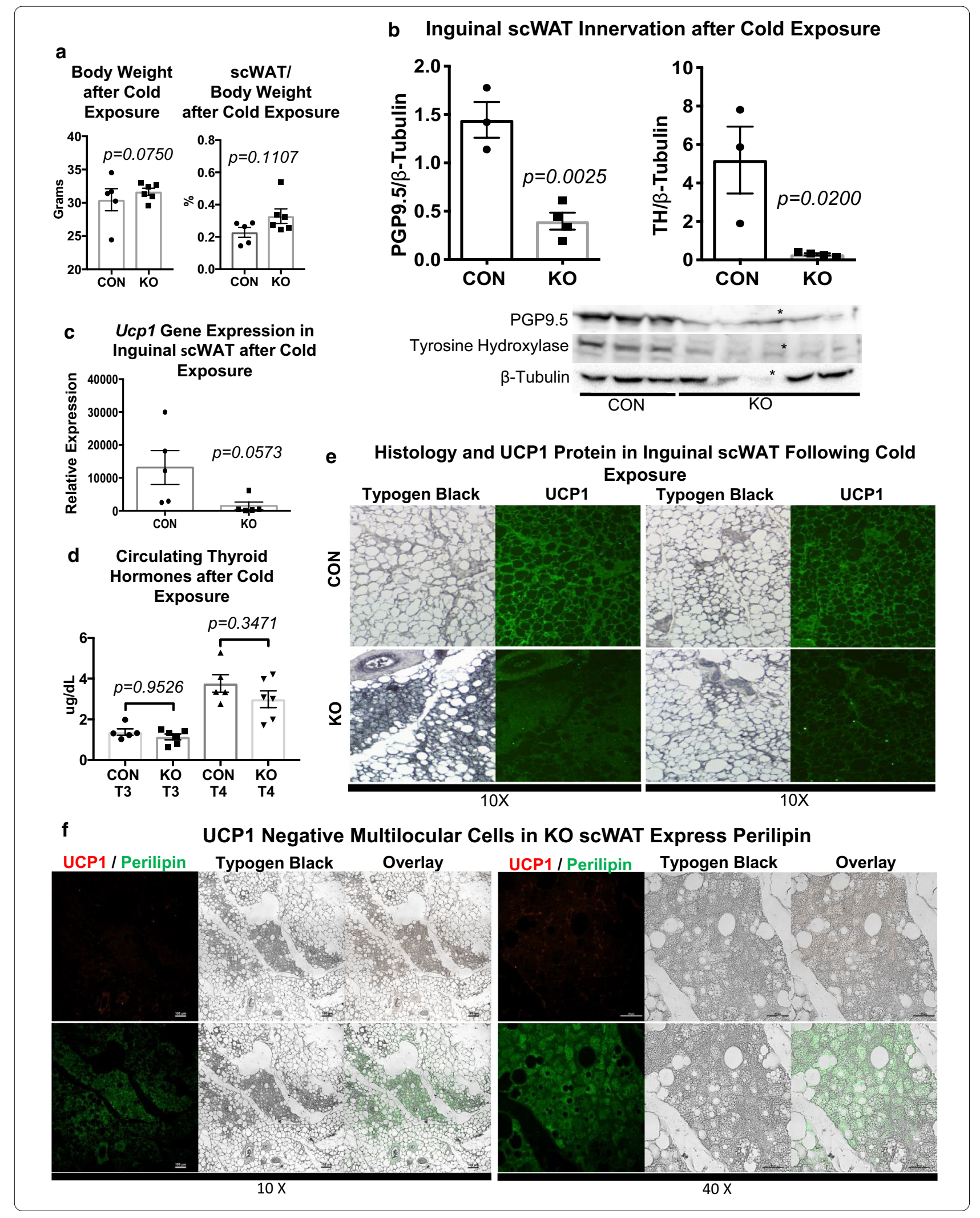


and $\mathrm{KO}$ mice were placed on a HFD for 3-11 weeks, to assess adipose integrity and energy balance. At 3 weeks of HFD feeding animals were characterized in metabolic cages. HFD resulted in only a slight decrease in energy expenditure in $\mathrm{KO}$ mice compared to littermate controls $(p \leq 0.05)$ (Fig. 3a) as analyzed via waveform analysis over multiple $24 \mathrm{~h}$ periods. However, KO mice showed a higher respiratory exchange ratio (RER) than CON animals during the light cycle, indicative of preferential metabolism of carbohydrates over lipids for fuel $(p \leq 0.05)$ (Fig. 3b). These data fit with studies demonstrating that adipose nerves are important for lipolysis (Bartness et al. 2014) and that denervation would shift fuel preference to carbohydrates. These physiological differences between $\mathrm{CON}$ and $\mathrm{KO}$ animals were observed despite no difference in food intake or change in body weight, $(p=0.4755$, $p=0.2772$ ) (Fig. 3c, d) at early time points. After 6 weeks of HFD, KO mice displayed better glucose control compared to CON animals $(p=0.0165, p=0.0469)$ (Fig. 3e). Considering the higher RER displayed by KO mice, we attribute the favorable glucose control to a shift in fuel utilization toward carbohydrates instead of lipids (as nerve-induced lipolysis is likely blunted). By 11 weeks of HFD feeding, KO animals displayed greater adiposity than littermate controls, $(p=0.0408)$ (Fig. 3f), potentially due to the reduced innervation and loss of neural control of certain metabolic processes.

\section{Cold-induced neuroimmune cells (CINCs) are recruited to scWAT and express BDNF}

After demonstrating the significance of myeloid derived BDNF to scWAT innervation, we sought to determine which myeloid cells were the source of tissue BDNF. Given their multifaceted role in adipose tissue, being a source of BDNF in the brain (microglia), and the phenotype observed in a myeloid-lineage $\mathrm{KO}$, we hypothesized that monocytes/macrophages were the leading source of BDNF in scWAT. Since previous studies indicated that BDNF is increased in scWAT with noradrenergic stimu-

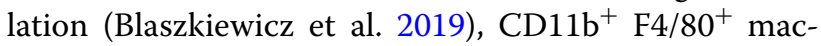
rophages were isolated from SVF of inguinal scWAT of room temperature and 5-day cold exposed C57BL/6 adult (12 week old) male mice. $B d n f$ gene expression did not differ between room temperature and cold exposed $\mathrm{CD}_{11 \mathrm{~b}}{ }^{+} \mathrm{F} 4 / 80^{+}$macrophages $(p=0.5796)$ (Fig. 4a). $\mathrm{F} 4 / 80+$ is considered a pan-macrophage marker, as such we considered it too broad to reveal phenotypic changes in the spectrum of macrophage populations in scWAT. Furthermore, F4/80+ is not the ideal marker of monocytes (macrophage precursors), which could be infiltrating the tissue in response to cold exposure. Based on these findings we applied a different approach to determining which myeloid cells are the source of scWAT
BDNF. Adult (12 week old) female control animals were maintained at room temperature or cold exposed for 10 days. Inguinal scWAT SVF was isolated and flow cytometrically analyzed using a custom antibody cocktail against immune cells. Surprisingly, cold exposure did not have an effect on either M1 or M2 ATMs $(p=0.8485, p=0.3387)$ (Fig. 4b). Instead, the greatest increase was in $\mathrm{Ly}_{6 \mathrm{C}}{ }^{+} \mathrm{CCR} 2^{+}$monocytes. Both Ly6C $\mathrm{C}^{+}$ and $\mathrm{CCR}^{+}$are markers of inflammatory monocyte migration (Getts et al. 2008). Following cold exposure, both $\mathrm{Ly}_{6 \mathrm{C}}{ }^{+} \mathrm{CCR} 2{ }^{+} \mathrm{Cx} 3 \mathrm{CR} 1^{-}$and $\mathrm{Ly}_{6 \mathrm{C}}{ }^{+} \mathrm{CCR} 2{ }^{+} \mathrm{Cx} 3 \mathrm{CR} 1^{+}$ populations increased in inguinal scWAT of female mice $(p=0.0401, p=0.0354)$, however, only the Ly $6 \mathrm{C}^{+} \mathrm{CCR} 2{ }^{+} \mathrm{Cx} 3 \mathrm{CR} 1^{+}$population showed a strong trend for increase in males $(p=0.9525$ and $p=0.0566)$ (Fig. 4c). In a separate cohort of adult male and female C57BL/6 mice, unbiased assessment using t-distributed Stochastic Neighbor Embedding (tSNE) revealed subpopulations of immune cells changing in propensity in scWAT with cold, and between male and female mice (cold and room temperature). Interestingly, the $\mathrm{Ly}_{6 \mathrm{C}}{ }^{+} \mathrm{CCR} 2^{+} \mathrm{Cx} 3 \mathrm{CR} 1^{+}$population, which we call coldinduced neuroimmune cells (CINCs) again increased in both male and female scWAT with cold (Fig. 4d).

To confirm that $\mathrm{Ly} 6 \mathrm{C}^{+} \mathrm{CCR} 2^{+} \mathrm{Cx} 3 \mathrm{CR} 1^{+}$monocytes/ macrophages were the source of BDNF, we FACS sorted out $\mathrm{Ly}_{6 \mathrm{C}}{ }^{+} \mathrm{CCR} 2^{+} \mathrm{Cx} 3 \mathrm{CR} 1^{+}$cells from inguinal scWAT SVF of 14 day cold exposed adult (12-13 week old) male C57BL/6 mice. We measured $B d n f$ gene expression in cold induced $\mathrm{Ly}_{6 \mathrm{C}}{ }^{+} \mathrm{CCR} 2{ }^{+} \mathrm{Cx} 3 \mathrm{CR} 1^{+}$cells and found that they showed a trend for increased expression of $B d n f$ compared to cold exposed non-myeloid cells $(p=0.1529)$ (Fig. 4e). We believe the previously observed increase in BDNF in adipose SVF ((Blaszkiewicz et al. 2019) and Fig. 1a) was due to infiltration of CINCs homing to scWAT upon cold exposure, and not an increase in percell BDNF levels.

Adr $\beta 3$ gene expression in $\mathrm{Ly}_{6 \mathrm{C}}{ }^{+} \mathrm{CCR} 2^{+} \mathrm{Cx} 3 \mathrm{CR} 1^{+}$cells confirmed the presence of norepinephrine (NE) receptor on these cells, indicating the potential to be responsive to SNS stimulation $(p=0.7788)$ (Additional file 1 : Figure S4A), a likely mode for promoting BDNF release to the tissue after cold exposure. Taken together, these data indicated that $\mathrm{Ly}_{6} \mathrm{C}^{+} \mathrm{CCR} 2^{+} \mathrm{Cx} 3 \mathrm{CR} 1^{+}$cells are cold-induced neuroimmune cells (CINCs) that increase in number in scWAT after cold, have the potential to be stimulated by sympathetic nerves, and express BDNF.

\section{Adipose lymph node and adipose lymphatics may play a role in recruitment of CINCs}

CINCs express the transient markers $\mathrm{Ly}_{6} \mathrm{C}^{+}$and $\mathrm{CCR} 2^{+}$, as well as $\mathrm{Cx} 3 \mathrm{CR} 1^{+}$, indicating that they are recruited to adipose tissue following cold stimulation as opposed to 
a

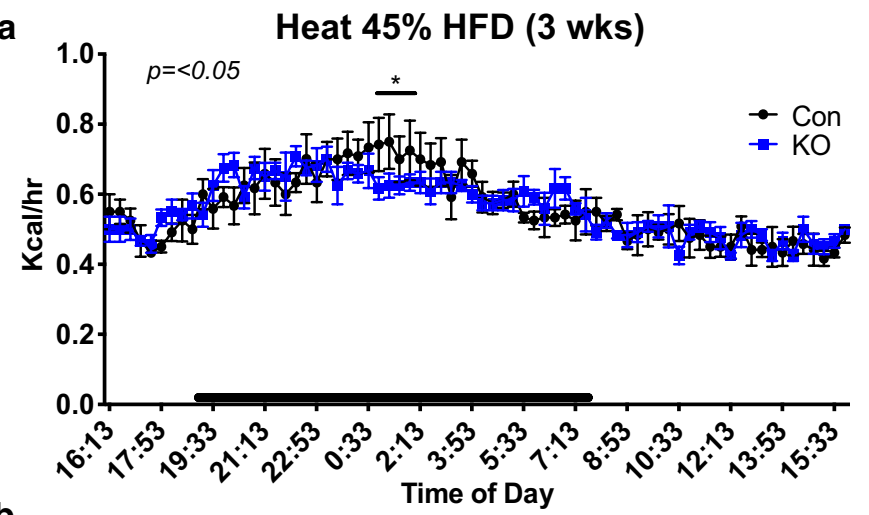

b

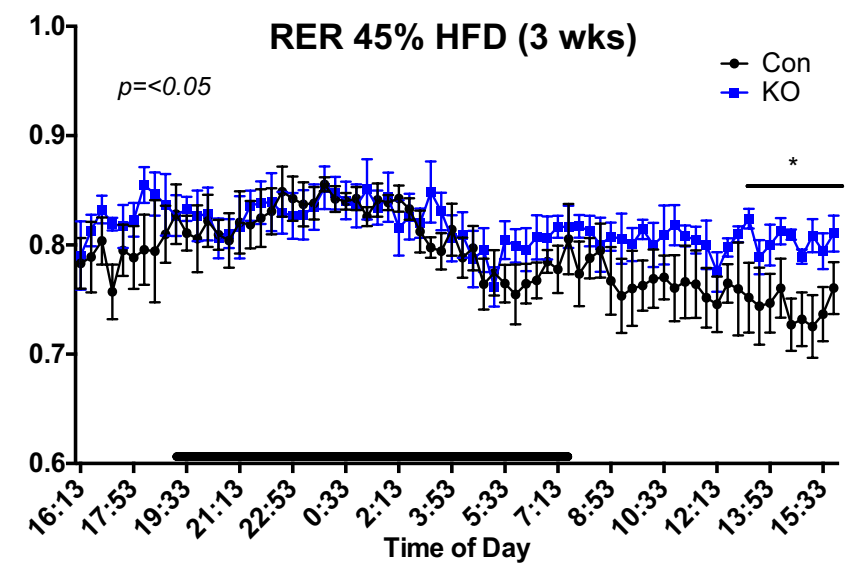

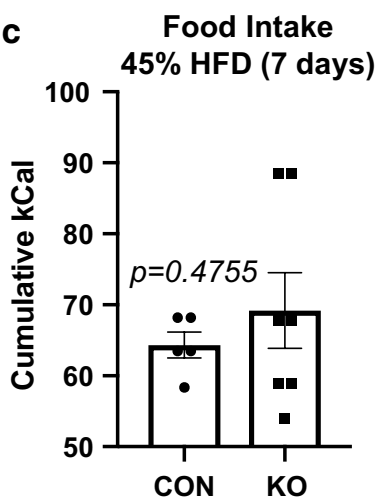

d \% Change Body Weight $45 \%$ HFD ( 7 days)

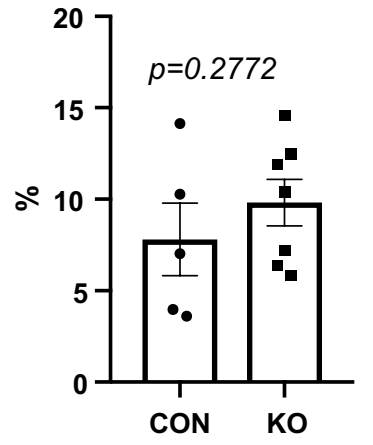

e

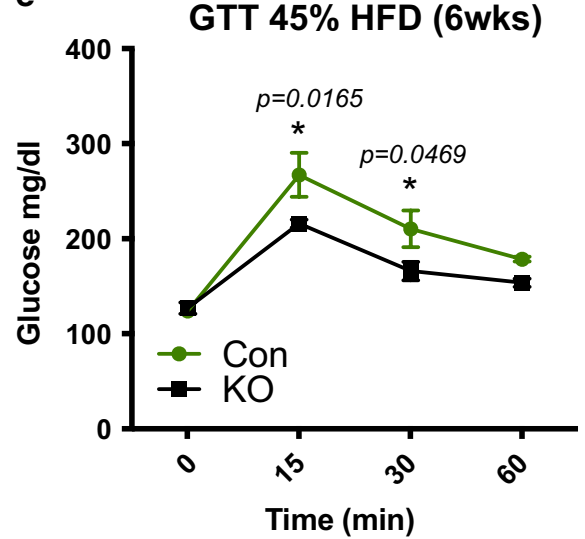

f scWAT/BW 45\% HFD (11wks)

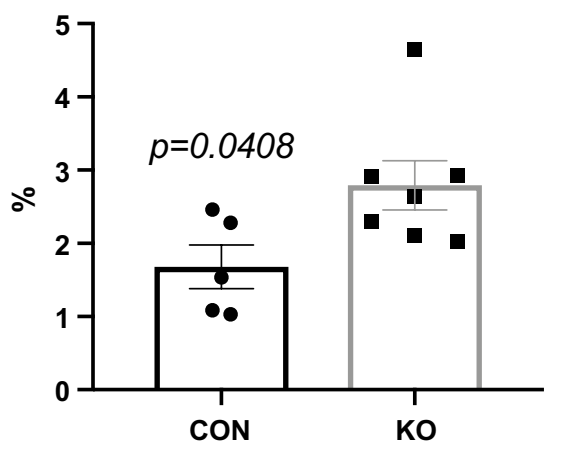

Fig. 3 LysMCre $^{ \pm .: B D N F^{-/-}}(\mathrm{KO})$ showed accelerated fat accumulation on a 45\% HFD. Adult (25 week old) male LysMCre ${ }^{-/-\ldots B D N F^{f / f l}}(\mathrm{CON})$ and $\mathrm{LysMCre}^{ \pm . .: B D N F^{--}}(\mathrm{KO})$ were challenged with a $45 \%$ HFD for 3 weeks before undergoing physiological assessment in metabolic cages (a, b). Energy expenditure as measured by heat was lower for $\mathrm{KO}$ versus $\mathrm{CON}$ only for a short period during the dark cycle, ${ }^{*} p \leq 0.05$ (a). Respiratory exchange as a ratio (RER) between the two groups, indicated greater use of carbohydrates for fuel by KO animals during the light cycle, $p \leq 0.05$ (b). Data presented as waveform analysis of measurements taken at 15 min increments for 3 days. Time of day is indicated on the $x$-axis, and animals were maintained on a $12 \mathrm{~h}$ light/dark cycle (black bars indicate dark cycle). Data analyzed by two-way repeated measures ANOVA with Fisher's LSD test; $\mathrm{N}=4$ per group. Adult (25 week old) male CON and KO animals were placed on a 45\% HFD, daily food intake (represented as cumulative food intake), $p=0.4755$ (c) was measured for the 1st week of HFD feeding. Percent change in body weight $p=0.2772$ (d) was measured for the first 7 days of HFD feeding. Data were analyzed by two-tailed Student's T-Test, $N=5$ CON, N = $7 \mathrm{KO}$. Glucose tolerance testing was performed at 6 weeks of HFD feeding, $p=0.0165$ at $15 \mathrm{~min}, p=0.0469$ at $30 \mathrm{~min}$ (e). Data were analyzed by Two-way ANOVA, with Tukey's multiple comparisons test, $\mathrm{N}=5 \mathrm{CON}, \mathrm{N}=5 \mathrm{KO}$. Adiposity was measured for CON and $\mathrm{KO}$ animals after 11 weeks of HFD feeding as a percentage of scWAT over body weight $p=0.0408$ (f). Data were analyzed by two-tailed Student's T-Test, $N=5$ CON, N=7 KO. For all error bars are SEMs 
being tissue resident immune cells. Immune cells are generally recruited to tissue through vasculature upon chemoattract release from target tissue. To further investigate dynamics of CINC recruitment to adipose tissue we utilized a Cx3CR1-EGFP reporter mouse. Whole mount imagining of axillary adipose tissue clearly demonstrated that $\mathrm{Cx} 3 \mathrm{CR} 1^{+}$macrophages were present at the surface of and within the adipose lymph node (LN; Fig. 5a, b). 3D reconstruction of adipose LN imaging with depth coding allowed us to visualize $\mathrm{Cx} 3 \mathrm{CR} 1^{+}$macrophages present on the capsule as well as within the cortex of the LN (Fig. 5b, middle and right panel). Furthermore, Cx3CR1 ${ }^{+}$ macrophages were enriched in adipose lymphatics (Fig. 5c left panel, yellow arrow) compared to blood vasculature (Fig. 5c left panel, red arrow). We took advantage of innate autofluorescence to visualize vasculature in these samples, and although blood and lymph vasculature are somewhat morphologically similar, the bulbous sacs found at capillary terminals are a unique feature of lymphatic vasculature only (Fig. $5 \mathrm{c}$ middle and right panels, bulbous sacs outlined in white). These lymphatics were the vessels that predominantly contained Cx3CR $1^{+}$ cells, and not the blood vasculature.

Confocal imaging of Cx3CR $1^{+}$macrophages on lymphatic endothelium clearly demonstrated that these cells have a distinct morphology (Fig. $5 \mathrm{~d}$ left panel). The cell bodies are elongated with cytoplastic extensions creating a spindeloid shape associated with alternatively activated macrophages (McWhorter et al. 2013). 3D reconstruction with depth coding following confocal imaging of adipose lymph vessels revealed that $\mathrm{Cx} 3 \mathrm{CR} 1^{+}$macrophages did not merely interact with lymph endothelial cells but were present within the lumen of the vessels (Fig. $5 \mathrm{~d}$, middle and right panels). $\mathrm{Cx} 3 \mathrm{CR} 1^{+}$macrophages were present in greater numbers around and within the lymphatics of adipose (Fig. 5e), and as previously reported were also associated with adipose nerves (Fig. 5f) (Pirzgalska et al. 2017). Taken together, these data indicated that Cx $3 \mathrm{CR} 1^{+}$macrophages are transported by the lymphatic vasculature to scWAT.

\section{Discussion}

Here we present evidence of the necessity for myeloidderived BDNF in maintaining inguinal scWAT innervation. Loss of BDNF from LysM ${ }^{+}$myeloid cells resulted in a decrease in total innervation of the inguinal adipose tissue as measured by protein levels of the pan-neuronal marker PGP9.5, and a near complete denervation of sympathetic nerves (as measured by $\mathrm{TH}$ protein expression). We attribute this 'genetic denervation' as a cause for the observed decrease in energy expenditure exhibited under basal conditions, impaired thermogenic potential evidenced by lack of UCP1 induction and increased WAT mass during cold stimulation, and worsened response to a high-fat, high-sugar diet. These phenotypes fit with the known roles of adipose nerves in regulating proper adipogenesis, lipolysis, thermogenesis and overall metabolic health in adipose tissues. Although adaptive thermogenesis is controlled by the CNS, intact peripheral nerves are required for a thermogenic response in BAT and scWAT, as demonstrated by numerous surgical and chemical denervation studies.

Diet-induced obesity results in chronic low-grade adipose inflammation due to infiltration of pro-inflammatory immune cells to the tissue, and ATM content increases from 10 to $15 \%$ (in lean mice) to $50 \%$ with obesity (Weisberg et al. 2003; Xu et al. 2003b). In addition, phenotypic switching of $\mathrm{CD} 4^{+} \mathrm{T}$ cells and recruitment of $\mathrm{T}$ cell and $\mathrm{B}$ cells precedes macrophage

\footnotetext{
(See figure on next page.)

Fig. 4 Cold induced neuroimmune cells (CINCs) home in to inguinal scWAT and express Bdnf. Adult (12 week old) male C57BL/6 were either maintained at room temperature (RT) or cold exposed $\left(5^{\circ} \mathrm{C}\right)$ for 5 days, ATMs from inguinal scWAT depots were isolated using magnetic-activated cell sorting (MACS) by positive selection of $\mathrm{CD} 11 \mathrm{~b}^{+}$followed by F4/80+ cells. Bdnf gene expression in doubly labeled $\mathrm{CD} 11 \mathrm{~b}^{+} \mathrm{F} 4 / 80^{+}$macrophages was compared between RT and cold exposed animals, $p=0.5796$ (a). Data were analyzed by two-tailed Student's T-Test, $N=4$ per group. Adult ( 12 week old) female control animals were either maintained at room temperature (RT) or cold exposed $\left(5^{\circ} \mathrm{C}\right)$ for 10 days, SVF from bilateral inguinal scWAT was isolated and FACS sorted using a 20 cell surface marker panel for myeloid lineage immune cells (b, c). Changes in M1/M2 polarity, RT versus cold M1 macrophages $p=0.8485$, and RT versus cold M2 $p=0.3387(\mathbf{b})$ and Ly6C ${ }^{+} \mathrm{CCR} 2^{+} \mathrm{C} \times 3 \mathrm{CR} 1^{-}$and $\mathrm{Ly} 6 \mathrm{C}^{+} \mathrm{CCR} 2^{+} \mathrm{C} \times 3 \mathrm{CR} 1^{+}$macrophage precursors/monocytes (c, left panel) were measured between RT and cold exposed animals, $p=0.0401$ and $p=0.0354$, respectively. Adult (12-13 week old) male C57BL/6 were either maintained at room temperature (RT) or cold exposed $\left(5^{\circ} \mathrm{C}\right)$ for 14 days; SVF from bilateral inguinal scWAT was isolated and FACS sorted; $\mathrm{Ly}_{6 \mathrm{C}}{ }^{+} \mathrm{CCR} 2^{+} \mathrm{C} \times 3 \mathrm{CR} 1^{-}$and $\mathrm{Ly}_{6 \mathrm{C}}{ }^{+} \mathrm{CCR} 2^{+} \mathrm{C} \times 3 \mathrm{CR} 1^{+}$cells were compared between $\mathrm{RT}$ and cold exposed animals, $p=0.9525$ and $p=0.0566$, respectively (c, right panel). Data were analyzed by two-tailed Student's T-Test, $N=3-4$ per group for both sexes. Adult male (M) and female (F) control animals were either maintained at room temperature (RT) or cold exposed $\left(5^{\circ} \mathrm{C}\right)$ for 10 days, SVF from bilateral inguinal scWAT was isolated and FACS sorted using a 20 cell surface marker panel for myeloid lineage immune cells ( $N=5$ per group). t-Distributed Stochastic Neighbor Embedding (tSNE) analysis was performed to identify myeloid lineage cell population changes in response to cold exposure; $\mathrm{Ly}_{6 \mathrm{C}}{ }^{+} \mathrm{CCR} 2{ }^{+} \mathrm{Cx} 3 \mathrm{CR} 1^{+}$were identified for both sexes as adipose CINCs $(\mathbf{d})$. Bdnf gene expression measured in Ly6C ${ }^{+} \mathrm{CCR} 2{ }^{+} \mathrm{Cx} 3 \mathrm{CR} 1^{+}$cells indicated that these infiltrating cells express Bdnf, $p=0.1529$ (e). Data analyzed by two-tailed Student's T-Test, $N=4$ per group. For all error bars are SEMs. ${ }^{*} p<0.05,{ }^{* *} p<0.01,{ }^{* * *} p<0.001,{ }^{* * *} p<0.0001$
} 
a

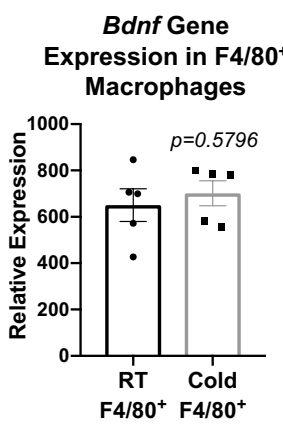

b

\section{Macrophage Polarity}

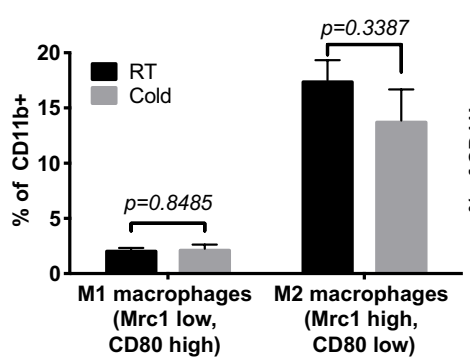

c

CINC Recruitment to Inguinal scWAT Following Cold Exposure

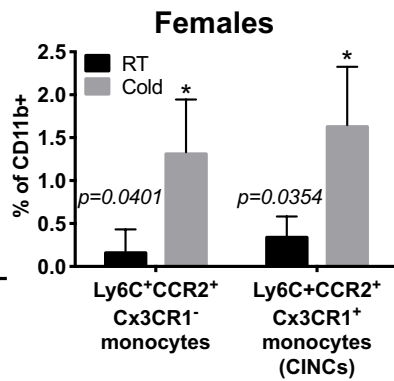

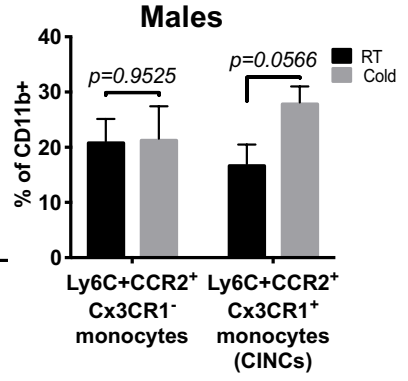

d

tSNE Analysis of Male/Female Cold Induced Immune Changes in Inguinal scWAT
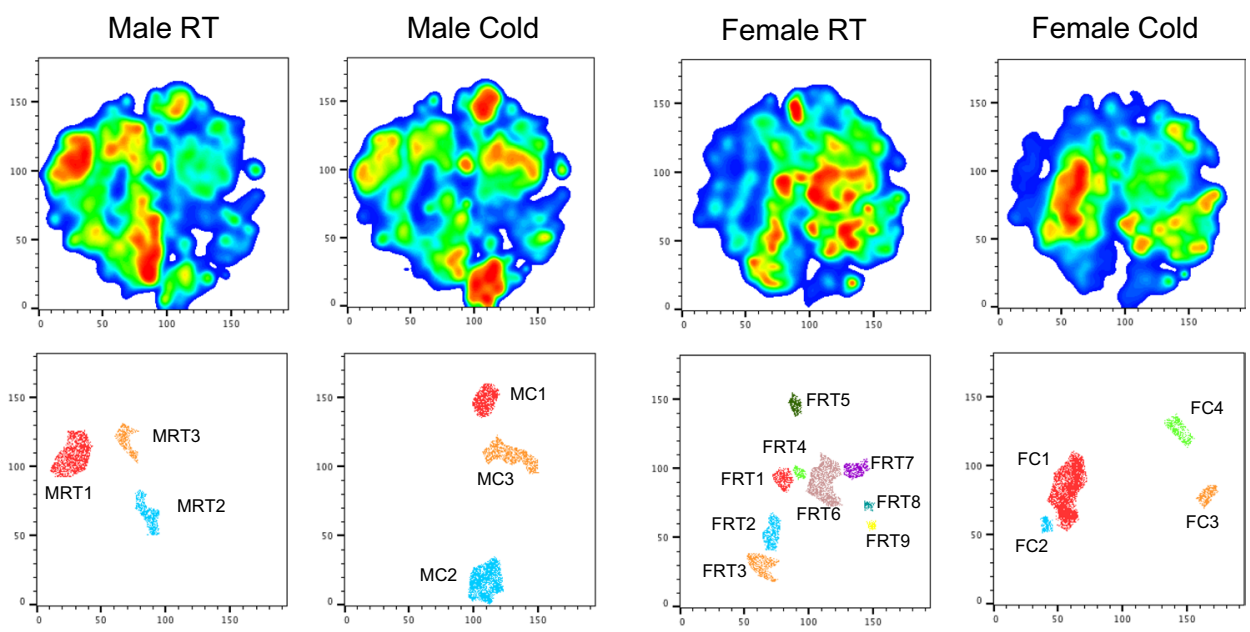

\begin{tabular}{|c|c|c|c|c|}
\hline Population & $\%$ & $\begin{array}{l}\text { Predicted } \\
\text { Identity }\end{array}$ & Markers & \\
\hline MRT1 & 9.2 & Myeloid & $\mathrm{CD} 11 \mathrm{~b}^{+} \mathrm{CD} 62 \mathrm{~L}^{+}$ & Present in RT, Lost on Cold \\
\hline MRT2 & 3.8 & APC & $\mathrm{CD} 11 \mathrm{~b}^{\text {neg }} \mathrm{MHC}^{+}$ & Present in RT, Lost on Cold \\
\hline MRT3 & 2.4 & Myeloid & CD11b+CD62Lneg & Present in RT, Lost on Cold \\
\hline MC1 & 5.6 & $T$ cells & $\mathrm{CD}_{11 \mathrm{~b}^{\text {neg }}} \mathrm{CD}^{+}$ & Appear on cold \\
\hline MC2 & 11.4 & CINCs & $\mathrm{CD} 11 \mathrm{~b}^{+} \mathrm{CCR} 2^{+} \mathrm{C} \times 3 \mathrm{CR} 1^{+}$ & Appear on cold \\
\hline MC3 & 5.8 & $T$ cells & CD11 $\mathrm{b}^{\text {neg }} \mathrm{CD} 3+$ & Appear on cold \\
\hline FRT1 & 2.4 & $B$ cells & $\mathrm{CD} 11 \mathrm{~b}^{\text {neg }} \mathrm{CD} 19^{+}$ & Present in RT, Lost on Cold \\
\hline FRT2 & 2.9 & Monocyte & CD11 $\mathrm{b}^{+}$Ly6C $\mathrm{C}^{+}$ & Present in RT, Lost on Cold \\
\hline FRT3 & 3.2 & APC & CD11 $\mathrm{b}^{\text {neg NK1. }} 11^{+} \mathrm{MHC}^{+}$ & Present in RT, Lost on Cold \\
\hline FRT4 & 0.9 & APC & CD11 $\mathrm{b}^{\text {neg }} \mathrm{CD} 11 \mathrm{C}^{+}$ & Present in RT, Lost on Cold \\
\hline FRT5 & 1.8 & APC & CD11 $\mathrm{b}^{\text {neg }} \mathrm{CD} 62 \mathrm{~L}^{+} \mathrm{L} y 6 \mathrm{C}^{+} \mathrm{MHC}$ mid & Present in RT, Lost on Cold \\
\hline FRT6 & 7.7 & $T$ cells & CD11 $\mathrm{b}^{\text {neg }} \mathrm{CD} 3+$ & Present in RT, Lost on Cold \\
\hline FRT7 & 2.1 & $T$ cells & CD11 $\mathrm{b}^{\text {neg }} \mathrm{CD} 3+$ & Present in RT, Lost on Cold \\
\hline FRT8 & 0.6 & $T$ cells & CD11 $\mathrm{b}^{\text {neg }} \mathrm{CD} 3+$ & Present in RT, Lost on Cold \\
\hline FRT9 & 0.6 & APC & $\mathrm{CD} 11 \mathrm{~b}^{+} \mathrm{CD} 11 \mathrm{c}^{+}$ & Present in RT, Lost on Cold \\
\hline FC1 & 19.2 & $B$ cells & CD11 $\mathrm{b}^{\text {neg }} \mathrm{CD} 19^{+}$ & Appear on cold \\
\hline $\mathrm{FC} 2$ & 1.1 & $B$ cells & CD11 $\mathrm{b}^{\text {neg }} \mathrm{CD} 19^{+}$ & Appear on cold \\
\hline $\mathrm{FC} 3$ & 2.3 & CINCs & $\mathrm{CD} 11 \mathrm{~b}^{+} \mathrm{CCR} 2^{+} \mathrm{C} \times 3 \mathrm{CR} 1^{+}$ & Appear on cold \\
\hline $\mathrm{FC} 4$ & 2.5 & $T$ cells & $\mathrm{CD}_{11 \mathrm{~b}^{\text {neg }}} \mathrm{CD}^{+}$ & Appear on cold \\
\hline
\end{tabular}

\section{e Bdnf Gene Expression in Ly6C+CCR2+Cx3CR1 ${ }^{+}$ Macrophages (CINCs)}

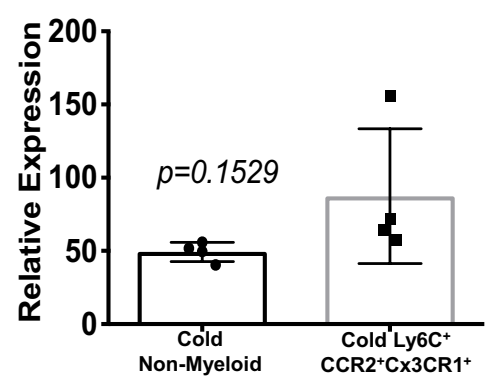


infiltration, and obesity macrophage polarity skews to a more inflammatory phenotype.

We initially hypothesized that anti-inflammatory (M2) ATMs were the source of scWAT BDNF. However, we observed no changes in M1 or M2 populations in scWAT after cold exposure. These M1 and M2 designations are an oversimplification of the diversity of macrophage populations and represent diverse subsets of cells with unique molecular signatures. Instead of changes in $\mathrm{M} 1$ or $\mathrm{M} 2$, we saw an increase in $\mathrm{Ly}_{6} \mathrm{C}^{+} \mathrm{CCR} 2^{+} \mathrm{Cx} 3 \mathrm{CR} 1^{+}$monocytes in scWAT of both male and female cold-exposed mice. We have named these cells CINCs since they are recruited to scWAT by cold and express BDNF. Surprisingly, it would appear that CINCs are a pro-inflammatory cell type as $\mathrm{Ly}_{6} \mathrm{C}^{+}$and $\mathrm{CCR}^{+}$are markers of inflammatory monocytes. Although pro-inflammatory cell infiltration to adipose tissue is usually a harbinger of metabolic dysfunction, an acute inflammatory response is necessary in wound healing and tissue remodeling, including for nerve repair (as is well documented in nerve injury studies). Only chronic, ongoing inflammation would be detrimental and causative of insulin resistance.

On the other hand, the $\mathrm{Cx} 3 \mathrm{CR} 1^{+}$macrophages we identified in adipose lymphatics exhibited features (such as elongated cell bodies) that are morphologically attributed to M2 or anti-inflammatory macrophages (McWhorter et al. 2013), further underscoring the incredible diversity of macrophage characterization in adipose. By utilizing an unbiased 20 antibody labeling approach to assess adipose SVF, we have discovered subsets of myeloid cells that respond to these particular environmental stimuli, providing further granularity to the myriad of immune cells types active in adipose.

Recently, a CX3CR $1^{+}$population of macrophages had been described in association with sympathetic nerves in adipose tissue (Pirzgalska et al. 2017). These sympathetic nerve associated macrophages (SAMs) were found to regulate catecholamine levels on adipose tissue by phagocytosing and degrading norepinephrine (NE) (Pirzgalska et al. 2017). Whether SAMs are the same cells as our
CINCs remains uncertain. Similar to CINCs, SAMs do exhibit pro-inflammatory markers, and a distinct morphology similar to the $\mathrm{Cx} 3 \mathrm{CR} 1^{+}$macrophages we identified in the adipose lymphatics. SAMs home to WAT in the obese state, while conversely, we see CINCs home to WAT with cold/noradrenergic-stimulation which tends to be metabolically healthy. Given that these two populations home to WAT in different conditions, this could indicate that the two immune cell types may have opposing roles, including potential for phagocytosing nerve debris for SAMs and stimulating nerve regeneration for CINCs. Fitting with this view, SAMs sequester and degrade NE, while CINCs express BDNF, thus promoting nerve plasticity.

On the other hand, $\mathrm{Cx} 3 \mathrm{CR} 1^{+}$macrophages have been shown to play diverse and even opposing roles in the intestines (Regoli et al. 2017), a phenotypic plasticity which may also be present in adipose tissue. One thing that is clear is the M1/M2 paradigm of ATM classification is an oversimplification of the functionally distinct populations of macrophages active in adipose tissue. Further markers beyond $\mathrm{Cx} 3 \mathrm{CR} 1^{+}$are necessary to fully understand and phenotype the rich variety of macrophages in adipose. Compounding the difficulty in clearly delineating macrophage populations is that macrophage activation is a dynamic process. Phenotypic switching appears to be sequential, responding to microenvironment stimuli (Stout et al. 2005) and may be dependent on spatiotemporal differences in tissue resident immune cell subtypes (Lumeng et al. 2008).

Since CINCs home into adipose tissue, we used a Cx3CR1-EGFP reporter mouse to visualize how this happens. Immune cells are recruited to tissues via vasculature, however, we found it surprising that in adipose it appeared that lymphatic and not blood vasculature plays a more important recruitment role for CINCs. Strikingly, the majority of $\mathrm{Cx} 3 \mathrm{CR} 1^{+}$cells were contained within the lymph node and lymphatic vessels of adipose tissue. Because lymph flows in a unidirectional manner, the lymphatic system is often overlooked as a source of

\footnotetext{
(See figure on next page.)

Fig. 5 Cx3CR1 Cells in Adipose Transit via Lymphatics. Wholemount imaging of female (a-e) and male (f) axillary scWAT from Cx3CR1-EGFP reporters mice. $\mathrm{Cx} 3 \mathrm{CR} 1^{+}$cells (green) in lymph node captured by widefield microscopy at $10 \mathrm{X}$ (a). Cx3XR1 ${ }^{+}$cells were shown to occupy the entire depth of the lymph node, captured by confocal microscopy at 20X (b), represented as a z-maximum projection (Glow LUT) (b, left) and 3D reconstruction (depth coded) at two angles (b, middle and right.) Cx3CR ${ }^{+}$cells (green) line lymphatic vasculature (morphologically distinguished from blood vasculature by the bulbous sacs on initial lymphatics, yellow arrow and outlined in white) but are absent in blood vasculature (red arrow) (c). Captured by widefield microscopy at 10X and 40X. Cx3CR ${ }^{+}$cells (Glow LUT) imaged by confocal microscopy at 63X were shown to reside on lymph vessel endothelium and were present within the lumen (d). Z-maximum projection of lymph vessel (d, left) and 3D reconstruction (depth coded) at two angles: looking down z-axis (d, middle) and looking down the x-axis (d, right) with vessel lumen identified by arrow. Tiled z-max projection captured on confocal at 20X demonstrates that Cx3CR ${ }^{+}$cells (white) are found throughout the lymphatic network in scWAT (e). $\mathrm{Cx} 3 \mathrm{CR} 1^{+}$cells (green) reside around nerve bundles marked by the pan-neuronal marker PGP9.5 (magenta) as captured by widefield microscopy at $40 X(\mathbf{f})$
} 
a

\section{Adipose Lymph Node}

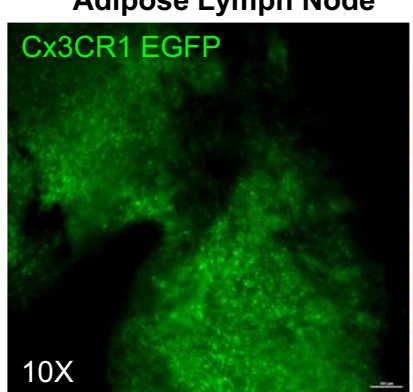

C

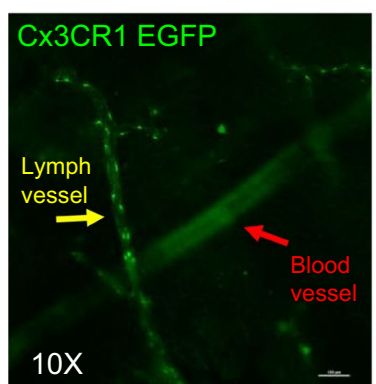

b

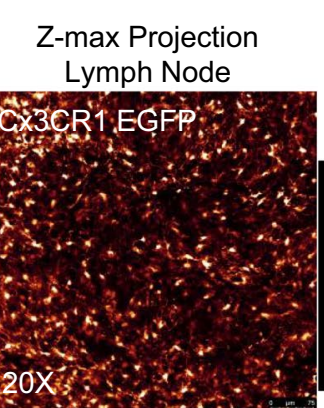

Imaging with Depth Coding: Cx3CR1 Cells Present on Capsule and Within Cortex of Adipose Lymph Node

Depth Coding: 3D

Reconstruction of Lymph Node

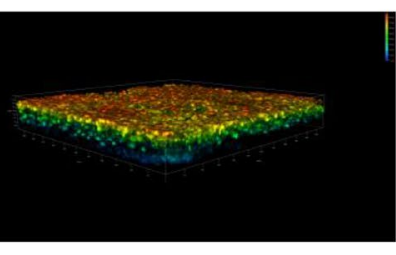

Depth Coding: 3D

Reconstruction of Lymph Node

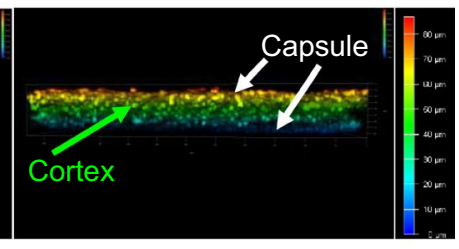

\section{Adipose Lymphatic Vessels}
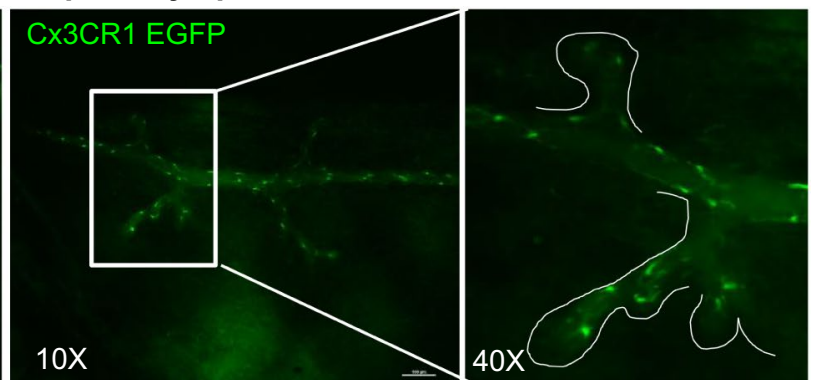

d Imaging with Depth Coding: Cx3CR1 Cells on Lymphatic Endothelium and in Lumen

Z-max Projection

Lymphatic Vessel

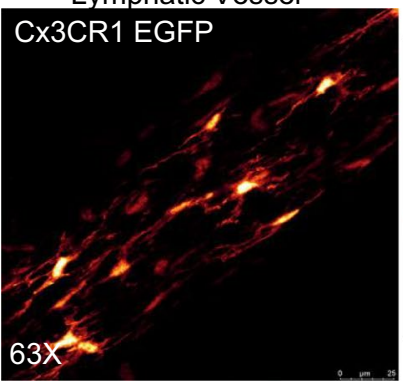

Depth Coding: 3D Reconstruction Lymphatic Vessel (plane of view: xyz)

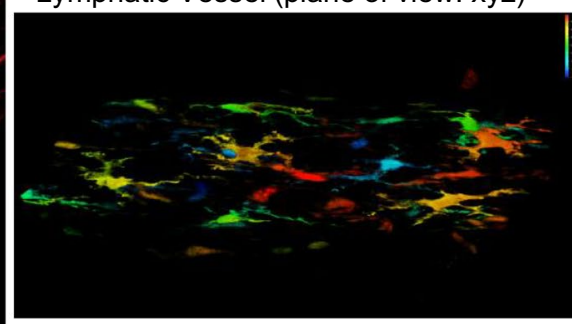

Depth Coding: 3D Reconstruction of Lymphatic Vessel (plane of view: zxy)

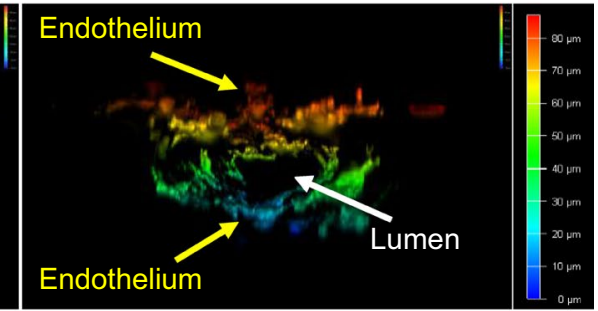

e

Cx3CR1 Cells in Adipose Lymphatics

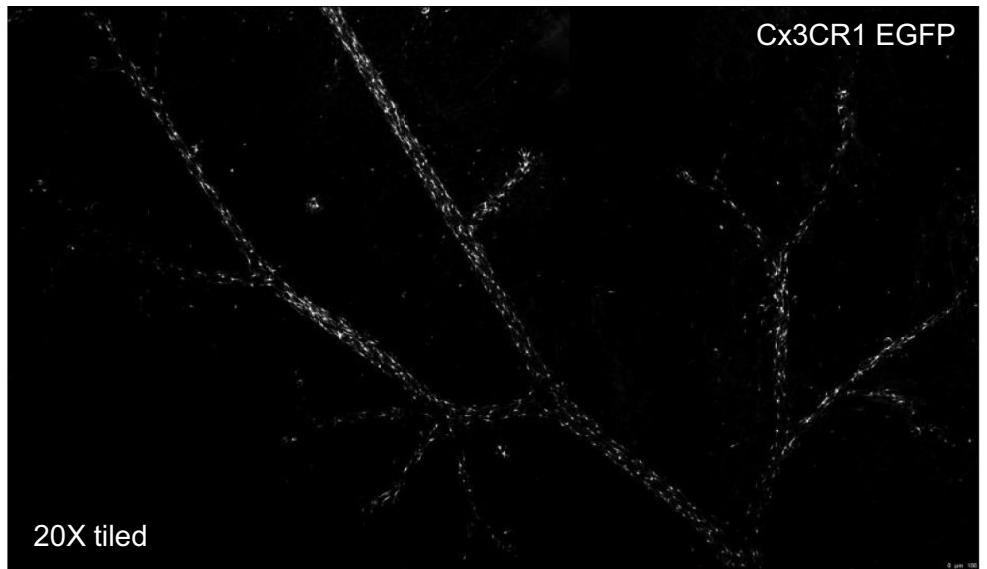

F. Cx3CR1 Cells Associated with Nerve Bundles in Adipose

CX3CR1 EGFP

PGP9.5

$40 X$ 
bidirectional crosstalk. In fact, lymphatic cells are not all destined for unidirectional trafficking. Leukocytes can also exit lymphatic vasculature and enter surrounding tissues (Jackson 2019).

We have previously reported increased innervation around LNs in adipose following cold exposure (Blaszkiewicz et al. 2019), while others have shown that browning commonly occurs around LNs (Dichamp et al. 2019). Furthermore, all lymph nodes in the body are surrounded by adipose tissue, which is activated during an immune response (Pond and Mattacks 2002). Together these data underscore the potential crosstalk between nerves, adipocytes, and leukocytes in scWAT, potentially via lymphatic communication. Regardless of whether or not CINCs are recruited to or merely drained by lymphatic vessels, the importance of the lymphatic system in transporting adipose immune cells is underscored by our current findings.

We postulate that CINCs contribute to nerve remodeling under noradrenergic stimulation, leading to BDNF release (Additional file 1: Figure S4B). Cao et al. have recently suggested that sympathetic nerve plasticity is dependent on cold-induced, adipose-derived NGF (Cao et al. 2018). Although they provide evidence that NGF is involved to some degree in promoting cold induced sympathetic nerve density and browning of scWAT, the cellular source of NGF was ambiguous (our data indicate it is produced more by mature adipocytes than SVF cells, and thus may be promoting innervation of the adipocytes and not the SVF). After determining that NGF gene expression increased in the first couple of days of cold exposure, Cao et al. used an NGF neutralizing antibody to prevent NGF activity and observed decreased sympathetic nerve density in response to cold. Their approach in preventing TrkA receptor function in adipose nerves and showing decreased browning and sympathetic nerve density lends credence to the notion that NGF plays a role in adipose innervation, similar to the role we observe for BDNF. Taken together it is clear that locally-derived nerve growth factors are important for maintaining proper brain-adipose communication and adipose innervation for metabolic control. Considering the variety of NFs and the multitude of cell types in adipose tissue it would not be surprising if both NGF and BDNF play a role in adipose innervation through different mechanisms, or through targeting different nerve subtypes, potentially to 'wire up' to distinct cellular targets. Promoting innervation of a specific axonal subtype to target a specific cell in the tissue may in fact be accomplished by coordinated secretion of a given growth factor by the target cell type; whereby mature adipocytes secrete NGF to 'wire up' adipocytes to TrkA ${ }^{+}$axons, whereas SVF immune cells secrete BDNF to 'wire up' immune cells to $\operatorname{TrkB}^{+}$axons.
The role of BDNF in peripheral nerve health is often overlooked in lieu of the overwhelming focus on central BDNF action. However, BDNF is known to play an important role in peripheral nerve regeneration, as reviewed by McGregor \& English (McGregor and English 2018). Following peripheral nerve injury local sources of secreted BDNF include not only dorsal root ganglia neurons, but also support cells, including Schwann cells (McGregor and English 2018). Cx3CR $1^{+}$macrophages have also been shown to play a crucial role in peripheral nerve regeneration by regulating Schwann cell dynamics in mice and humans (Stratton et al. 2018). These studies align with the data presented here and offer a new avenue of research in neuroimmune regulation of peripheral nerve plasticity.

\section{Conclusion}

In conclusion, we have demonstrated the importance of CINC immune cells for maintaining adipose innervation, particularly after cold exposure, which promotes CINC movement to adipose (likely via adipose lymphatic vasculature). CINCs express and likely secrete BDNF in response to cold-induced noradrenergic stimulation, thus promoting axonal survival and metabolic function in the tissue. Given these findings, it is clear that neuroimmune crosstalk in scWAT is important for nerve integrity, tissue function, and metabolic control.

\section{Supplementary information}

Supplementary information accompanies this paper at https://doi. org/10.1186/s10020-020-00254-3.

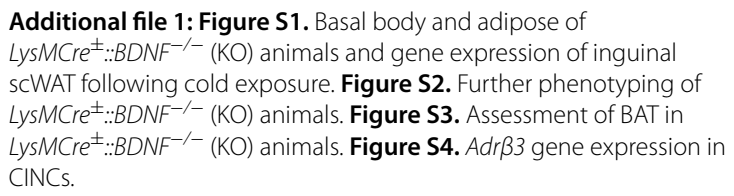

Additional file 2.

\section{Abbreviations}

ADR $\beta 3$ : $\beta$-3 Adrenergic receptor; ATMs: Adipose tissue macrophages; BAT: Brown adipose tissue; BDNF: Brain derived neurotrophic factor; BMI: Body mass index; CINCs: Cold induced neuroimmune cells; CNS: Central nervous system; CON: Control; FACS: Fluorescence-activated cell sorting; GWAS: Genome wide associated studies; HFD: High fat diet; KO: Knock-out; LN: Lymph node; MACS: Magnetic-activated cell sorting; NE: Norepinephrine; NFs: Neurotrophic factors; NGF: Nerve growth factor; NMJs: Neuromuscular junctions; NT-3: Neurotrophin-3; NT-4/5: Neurotrophin-4/5; PGP9.5: Protein gene product 9.5; RER: Respiratory exchange ratio; SAMs: Sympathetic nerve associated macrophages; scWAT: Subcutaneous white adipose tissue; SiLN: Subiliac lymph node; SNPs: Single nucleotide polymorphisms; SNS: Sympathetic

nervous system; SVF: Stromal vascular fraction; TH: Tyrosine hydroxylase; tSNE: T-distributed Stochastic Neighbor Embedding; UCP1: Uncoupling protein 1; VEGFa: Vascular endothelial growth factor a; WAT: White adipose tissue.

\section{Acknowledgements}

The authors wish to thank the following individuals from University of Maine: Brenda Kennedy-Wade and Prof. James Weber for assistance in the animal 
facility; Dawna Beane for paraffin embedding; Callie Greco, Cameron Fudge, and Sarah Berez for animal care. The authors also wish to thank Drs. Gregory Cox and Robert Burgess from Jackson Laboratory for sharing their NMJ assessment methods; Dr. Maribel Rios for expert advice; and Nicholas Cutter and Emma Bragdon for help with spinal, motor, and sensory nerve assessments.

\section{Authors' contributions}

MB designed experiments, analyzed data, and wrote the manuscript. EW and SK collected and analyzed histology data. SK and RA collected and analyzed data related to brown adipose tissue. JG conducted the flow cytometric analysis on adipose immune cells. YHT oversaw initial pilot experiments. KLT designed experiments, analyzed data, conceived of and oversaw the project, and wrote the manuscript. KLT is the guarantor of this work and, as such, had full access to all the data in the study and takes responsibility of the data and the accuracy of the data analysis. All authors read and approved the final manuscript.

\section{Funding}

For this project, the Townsend Lab was funded by start-up funds from the Office of the Vice President for Research at University of Maine, a Rising Tide Seed Grant from University of Maine, a Junior Faculty Award from the American Diabetes Association (1-14-JF-55), and an NIH NIDDK 1R01DK11432001A1. The Godwin lab is supported by a NIH COBRE award (P20GM104318).

\section{Availability of data and materials}

Data available upon request.

\section{Ethics approval and consent to participate}

All animal studies were IACUC approved at University of Maine.

\section{Consent for publication}

All authors have consented for publication.

\section{Competing interests}

The authors do not have any competing interests to disclose.

\section{Author details}

${ }^{1}$ School of Biology and Ecology, University of Maine, Orono, ME, USA. ${ }^{2}$ Graduate School of Biomedical Science and Engineering, University of Maine, Orono, ME, USA. ${ }^{3}$ Joslin Diabetes Center, Harvard Medical School, Boston, MA, USA. ${ }^{4}$ Jackson Laboratory, Bar Harbor, ME, USA. ${ }^{5}$ MDI Biological Laboratory, Bar Harbor, ME, USA. ${ }^{6}$ The Ohio State University, 1014 Biomedical Research Tower, 460 W 12th Ave, Columbus, $\mathrm{OH} 43210, \mathrm{USA}$.

Received: 2 September 2020 Accepted: 1 December 2020

Published online: 09 December 2020

\section{References}

An JJ, Gharami K, Liao GY, Woo NH, Lau AG, Vanevski F, et al. Distinct role of long $3^{\prime}$ UTR BDNF mRNA in spine morphology and synaptic plasticity in hippocampal neurons. Cell. 2008;134(1):175-87.

An JJ, Liao GY, Kinney CE, Sahibzada N, Xu B. Discrete BDNF neurons in the paraventricular hypothalamus control feeding and energy expenditure. Cell Metab. 2015;22(1):175-88.

Araki S, Yamamoto Y, Dobashi K, Asayama K, Kusuhara K. Decreased plasma levels of brain-derived neurotrophic factor and its relationship with obesity and birth weight in obese Japanese children. Obes Res Clin Pract. 2014;8(1):e63-9.

Bartness TJ, Song CK. Brain-adipose tissue neural crosstalk. Physiol Behav. 2007;91(4):343-51.

Bartness TJ, Liu Y, Shrestha YB, Ryu V. Neural innervation of white adipose tissue and the control of lipolysis. Front Neuroendocrinol. 2014;35(4):473-93.

Bernhard F, Landgraf K, Kloting N, Berthold A, Buttner P, Friebe D, et al. Functional relevance of genes implicated by obesity genome-wide association study signals for human adipocyte biology. Diabetologia. 2013:56(2):311-22.

Blaszkiewicz M, Willows JW, Dubois AL, Waible S, DiBello K, Lyons LL, et al. Neuropathy and neural plasticity in the subcutaneous white adipose depot. PLOS ONE. 2019;14(9):e0221766.
Bowers RR, Festuccia WT, Song CK, Shi H, Migliorini RH, Bartness TJ. Sympathetic innervation of white adipose tissue and its regulation of fat cell number. Am J Physiol-Regul Integr Comp Physiol. 2004;286(6):R1167-75.

Cao Y, Wang H, Zeng W. Whole-tissue 3D imaging reveals intra-adipose sympathetic plasticity regulated by NGF-TrkA signal in cold-induced beiging. Protein Cell. 2018;9(6):527-39.

Desautels M, Dulos RA, Mozaffari B. Selective loss of uncoupling protein from mitochondria of surgically denervated brown adipose tissue of coldacclimated mice. Biochem Cell Biol. 1986;64(11):1125-34.

Dichamp J, Barreau C, Guissard C, Carriere A, Martinez Y, Descombes X, et al. $3 \mathrm{D}$ analysis of the whole subcutaneous adipose tissue reveals a complex spatial network of interconnected lobules with heterogeneous browning ability. Sci Rep. 2019;9(1):6684.

Duan W, Guo Z, Jiang H, Ware M, Li XJ, Mattson MP. Dietary restriction normalizes glucose metabolism and BDNF levels, slows disease progression, and increases survival in huntingtin mutant mice. Proc Natl Acad Sci USA. 2003;100(5):2911-6.

Dulloo AG, Miller DS. Energy balance following sympathetic denervation of brown adipose tissue. Can J Physiol Pharmacol. 1984a;62(2):235-40.

Dulloo A, Miller D. Energy balance following sympathetic denervation of brown adipose tissue. Can J Physiol Pharmacol. 1984b;62(2):235-40.

Elgazar-Carmon V, Rudich A, Hadad N, Levy R. Neutrophils transiently infiltrate intra-abdominal fat early in the course of high-fat feeding. J Lipid Res. 2008:49(9):1894-903.

Foster MT, Bartness TJ. Sympathetic but not sensory denervation stimulates white adipocyte proliferation. Am J Physiol Regul Integr Comp Physiol. 2006;291(6):R1630-7.

Fritsch B, Reis J, Martinowich K, Schambra HM, Ji Y, Cohen LG, et al. Direct current stimulation promotes BDNF-dependent synaptic plasticity: potential implications for motor learning. Neuron. 2010;66(2):198-204.

Gemma C, Bachstetter AD. The role of microglia in adult hippocampal neurogenesis. Front Cell Neurosci. 2013;7:229.

Getts DR, Terry RL, Getts MT, Muller M, Rana S, Shrestha B, et al. Ly6c+ "inflammatory monocytes" are microglial precursors recruited in a pathogenic manner in West Nile virus encephalitis. J Exp Med. 2008;205(10):2319-37.

Goss JR, O'Malley ME, Zou L, Styren SD, Kochanek PM, DeKosky ST. Astrocytes are the major source of nerve growth factor upregulation following traumatic brain injury in the rat. Exp Neurol. 1998;149(2):301-9.

Grant R, Youm YH, Ravussin A, Dixit VD. Quantification of adipose tissue leukocytosis in obesity. Methods Mol Biol. 2013;1040:195-209.

Gray JD, Milner TA, McEwen BS. Dynamic plasticity: the role of glucocorticoids, brain-derived neurotrophic factor and other trophic factors. Neuroscience. 2013;239:214-27.

Gray NE, Lam LN, Yang K, Zhou AY, Koliwad S, Wang JC. Angiopoietin-like 4 (Angptl4) protein is a physiological mediator of intracellular lipolysis in murine adipocytes. J Biol Chem. 2017;292(39):16135.

Harris RB. Sympathetic denervation of one white fat depot changes norepinephrine content and turnover in intact white and brown fat depots. Obesity (Silver Spring). 2012;20(7):1355-64.

Hausman GJ, Poulos SP, Richardson RL, Barb CR, Andacht T, Kirk HC, et al. Secreted proteins and genes in fetal and neonatal pig adipose tissue and stromal-vascular cells. J Anim Sci. 2006;84(7):1666-81.

Hui X, Gu P, Zhang J, Nie T, Pan Y, Wu D, et al. Adiponectin enhances coldinduced browning of subcutaneous adipose tissue via promoting M2 macrophage proliferation. Cell Metab. 2015;22(2):279-90.

Jackson DG. Leucocyte trafficking via the lymphatic vasculature-mechanisms and consequences. Front Immunol. 2019;10:471.

Kerschensteiner M, Gallmeier E, Behrens L, Leal W, Misgeld T, Klinkert WE, et al. Activated human $T$ cells, B cells, and monocytes produce brain-derived neurotrophic factor in vitro and in inflammatory brain lesions: a neuroprotective role of inflammation? J Exp Med. 1999;189(5):865-70.

Kleim JA, Chan S, Pringle E, Schallert K, Procaccio V, Jimenez R, et al. BDNF val66 met polymorphism is associated with modified experience-dependent plasticity in human motor cortex. Nat Neurosci. 2006;9(6):735-7.

Kobayashi H, Gleich GJ, Butterfield JH, Kita H. Human eosinophils produce neurotrophins and secrete nerve growth factor on immunologic stimuli. Blood. 2002;99(6):2214-20.

Lai SW, Chen JH, Lin HY, Liu YS, Tsai CF, Chang PC, et al. Regulatory effects of neuroinflammatory responses through brain-derived neurotrophic factor signaling in microglial cells. Mol Neurobiol. 2018;55(9):7487-99. 
Lambiase A, Bracci-Laudiero L, Bonini S, Bonini S, Starace G, D'elios MM, et al. Human CD4+T cell clones produce and release nerve growth factor and express high-affinity nerve growth factor receptors. J Allergy Clin Immunol. 1997;100(3):408-14.

Leon A, Buriani A, Dal Toso R, Fabris M, Romanello S, Aloe L, et al. Mast cells synthesize, store, and release nerve growth factor. Proc Natl Acad Sci USA. 1994;91(9):3739-43.

Liu J, Divoux A, Sun J, Zhang J, Clement K, Glickman JN, et al. Genetic deficiency and pharmacological stabilization of mast cells reduce dietinduced obesity and diabetes in mice. Nat Med. 2009;15(8):940-5.

Lumeng CN, Delproposto JB, Westcott DJ, Saltiel AR. Phenotypic switching of adipose tissue macrophages with obesity is generated by spatiotemporal differences in macrophage subtypes. Diabetes. 2008:57(12):3239-46.

Madduri S, Gander B. Schwann cell delivery of neurotrophic factors for peripheral nerve regeneration. J Peripher Nerv Syst. 2010;15(2):93-103.

McGregor CE, English AW. The role of BDNF in peripheral nerve regeneration: activity-dependent treatments and Val66Met. Front Cell Neurosci. 2018;12:522.

McWhorter FY, Wang T, Nguyen P, Chung T, Liu WF. Modulation of macrophage phenotype by cell shape. Proc Natl Acad Sci USA. 2013;110(43):17253-8.

Minokoshi Y, Saito M, Shimazu T. Sympathetic denervation impairs responses of brown adipose tissue to VMH stimulation. Am J Physiol. 1986;251 (5 Pt 2):R1005-8

Nakagawa T, Tsuchida A, Itakura Y, Nonomura T, Ono M, Hirota F, et al. Brainderived neurotrophic factor regulates glucose metabolism by modulating energy balance in diabetic mice. Diabetes. 2000;49(3):436-44.

Nakagomi A, Okada S, Yokoyama M, Yoshida Y, Shimizu I, Miki T, et al. Role of the central nervous system and adipose tissue BDNF/TrkB axes in metabolic regulation. NPJ Aging Mech Dis. 2015;1:15009.

Nielsen TS, Jessen N, Jorgensen JO, Moller N, Lund S. Dissecting adipose tissue lipolysis: molecular regulation and implications for metabolic disease. J Mol Endocrinol. 2014;52(3):R199-222.

Noga O, Englmann C, Hanf G, Grutzkau A, Seybold J, Kunkel G. The production, storage and release of the neurotrophins nerve growth factor, brain-derived neurotrophic factor and neurotrophin-3 by human peripheral eosinophils in allergics and non-allergics. Clin Exp Allergy. 2003;33(5):649-54.

Nonomura T, Tsuchida A, Ono-Kishino M, Nakagawa T, Taiji M, Noguchi H. Brain-derived neurotrophic factor regulates energy expenditure through the central nervous system in obese diabetic mice. Int J Exp Diabetes Res. 2001;2(3):201-9.

Parkhurst CN, Yang G, Ninan I, Savas JN, Yates JR 3rd, Lafaille JJ, et al. Microglia promote learning-dependent synapse formation through brain-derived neurotrophic factor. Cell. 2013;155(7):1596-609.

Pirzgalska RM, Seixas E, Seidman JS, Link VM, Sánchez NM, Mahú I, et al. Sympathetic neuron-associated macrophages contribute to obesity by importing and metabolizing norepinephrine. Nat Med. 2017;23(11):1309.

Pond CM, Mattacks CA. The activation of the adipose tissue associated with lymph nodes during the early stages of an immune response. Cytokine. 2002;17(3):131-9.

Rausch ME, Weisberg S, Vardhana P, Tortoriello DV. Obesity in C57BL/6J mice is characterized by adipose tissue hypoxia and cytotoxic T-cell infiltration. Int J Obes (Lond). 2008:32(3):451-63.

Regoli M, Bertelli E, Gulisano M, Nicoletti C. The multifaceted personality of intestinal CX3CR1 (+) macrophages. Trends Immunol. 2017:38(12):879-87.
Rios M, Fan G, Fekete C, Kelly J, Bates B, Kuehn R, et al. Conditional deletion of brain-derived neurotrophic factor in the postnatal brain leads to obesity and hyperactivity. Mol Endocrinol. 2001;15(10):1748-57.

Rost B, Hanf G, Ohnemus U, Otto-Knapp R, Groneberg DA, Kunkel G, et al. Monocytes of allergics and non-allergics produce, store and release the neurotrophins NGF, BDNF and NT-3. Regul Pept. 2005;124(1-3):19-25.

Roth CL, Elfers C, Gebhardt U, Muller HL, Reinehr T. Brain-derived neurotrophic factor and its relation to leptin in obese children before and after weight loss. Metabolism. 2013;62(2):226-34.

Sornelli F, Fiore M, Chaldakov GN, Aloe L. Adipose tissue-derived nerve growth factor and brain-derived neurotrophic factor: results from experimental stress and diabetes. Gen Physiol Biophys. 2009;28 Spec No:179-83.:179-83.

Stout RD, Jiang C, Matta B, Tietzel I, Watkins SK, Suttles J. Macrophages sequentially change their functional phenotype in response to changes in microenvironmental influences. J Immunol. 2005;175(1):342-9.

Stratton JA, Holmes A, Rosin NL, Sinha S, Vohra M, Burma NE, et al. Macrophages regulate Schwann cell maturation after nerve injury. Cell Rep. 2018;24(10):2561-72 e6.

Strissel KJ, DeFuria J, Shaul ME, Bennett G, Greenberg AS, Obin MS. T-cell recruitment and Th1 polarization in adipose tissue during diet-induced obesity in C57BL/6 mice. Obesity (Silver Spring). 2010;18(10):1918-25.

Tapia-Arancibia L, Rage F, Givalois L, Arancibia S. Physiology of BDNF: focus on hypothalamic function. Front Neuroendocrinol. 2004;25(2):77-107.

Terenghi G. Peripheral nerve regeneration and neurotrophic factors. J Anat. 1999;194(Pt 1):1-14.

Unger TJ, Calderon GA, Bradley LC, Sena-Esteves M, Rios M. Selective deletion of Bdnf in the ventromedial and dorsomedial hypothalamus of adult mice results in hyperphagic behavior and obesity. J Neurosci. 2007;27(52):14265-74.

Weisberg SP, McCann D, Desai M, Rosenbaum M, Leibel RL, Ferrante AW Jr. Obesity is associated with macrophage accumulation in adipose tissue. J Clin Invest. 2003;112(12):1796-808.

Willows JW, Blaszkiewicz M, Lamore A, Borer S, Dubois AL, Garner E, et al. Visualization and analysis of whole depot adipose tissue innervation. bioRxiv. 2019. https://doi.org/10.1101/788885.

Winer DA, Winer S, Shen L, Wadia PP, Yantha J, Paltser G, et al. B cells promote insulin resistance through modulation of $\mathrm{T}$ cells and production of pathogenic IgG antibodies. Nat Med. 2011;17(5):610-7.

Xu B, Xie X. Neurotrophic factor control of satiety and body weight. Nat Rev Neurosci. 2016;17(5):282-92.

Xu B, Goulding EH, Zang K, Cepoi D, Cone RD, Jones KR, et al. Brain-derived neurotrophic factor regulates energy balance downstream of melanocortin-4 receptor. Nat Neurosci. 2003a;6(7):736-42.

Xu H, Barnes GT, Yang Q, Tan G, Yang D, Chou CJ, et al. Chronic inflammation in fat plays a crucial role in the development of obesity-related insulin resistance. J Clin Invest. 2003b;112(12):1821-30.

\section{Publisher's Note}

Springer Nature remains neutral with regard to jurisdictional claims in published maps and institutional affiliations.

Ready to submit your research? Choose BMC and benefit from

- fast, convenient online submission

- thorough peer review by experienced researchers in your field

- rapid publication on acceptance

- support for research data, including large and complex data types

- gold Open Access which fosters wider collaboration and increased citations

- maximum visibility for your research: over 100M website views per year

At BMC, research is always in progress.

Learn more biomedcentral.com/submissions 